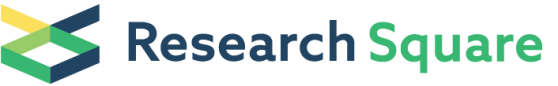 \\ Preprints are preliminary reports that have not undergone peer review. \\ They should not be considered conclusive, used to inform clinical practice, or referenced by the media as validated information.
}

\section{Novel bacterial chloromethane degraders of a living tree fern evidenced by 13C-chloromethane incubations}

Eileen Kröber ( $\nabla$ ekroeber@mpi-bremen.de)

Leibniz-Zentrum für Agrarlandschaftsforschung https://orcid.org/0000-0002-9729-9891

Sonja Wende

Leibniz-Zentrum fur Agrarlandschaftsforschung

Saranya Kanukollu

Leibniz-Zentrum fur Agrarlandschaftsforschung

Caroline Buchen-Tschiskale

Leibniz-Zentrum fur Agrarlandschaftsforschung

Ludovic Besaury

Génétique Moléculaire Génomique et Microbiologie: Genetique moleculaire genomique et microbiologie

Frank Keppler

Institute of Earth Sciences Heidelberg

Stéphane Vuilleumier

Génétique Moléculaire Génomique et Microbiologie: Genetique moleculaire genomique et microbiologie

Steffen Kolb

Leibniz-Zentrum fur Agrarlandschaftsforschung

Françoise Bringel

Génétique Moléculaire Génomique et Microbiologie: Genetique moleculaire genomique et microbiologie

\section{Research}

Keywords: Chloromethane, Phyllosphere, Rhizosphere, Stable Isotope Probing (DNA-SIP), 47

Metagenome-assembled genomes (MAGs), tree fern, one-carbon metabolism

Posted Date: March 17th, 2021

DOI: https://doi.org/10.21203/rs.3.rs-299001/v1

License: (c) (i) This work is licensed under a Creative Commons Attribution 4.0 International License.

Read Full License 
1 Novel bacterial chloromethane degraders of a living tree fern evidenced by ${ }^{13} \mathrm{C}$ -

3 Eileen Kröber ${ }^{1 \dagger}$, Sonja Wende ${ }^{1}$, Saranya Kanukollu ${ }^{1}$, Caroline Buchen-Tschiskale ${ }^{1+}$, Ludovic

4 Besaury $^{2^{*}}$, Frank Keppler ${ }^{3}$, Stéphane Vuilleumier ${ }^{2}$, Steffen Kolb ${ }^{1,4}$, Françoise Bringel ${ }^{2}$

5

$6 \quad{ }^{1}$ Microbial Biogeochemistry, RA Landscape Functioning, ZALF Leibniz Centre for

7 Agricultural Landscape Research, Müncheberg, Germany

8 t Present address: Max Planck Institute for Marine Microbiology, Bremen, Germany

9 + Present address: Johann Heinrich von Thünen-Institut, Institute of Climate-Smart

10 Agriculture, Braunschweig, Germany

$11{ }^{2}$ Génétique Moléculaire, Génomique, Microbiologie (GMGM), Université de Strasbourg,

12 UMR 7156 CNRS, Strasbourg, France

13 *Present address: Université de Reims Champagne-Ardenne, Reims, France

$14{ }^{3}$ Institute of Earth Sciences, Heidelberg University, Heidelberg, Germany

$15{ }^{4}$ Thaer Institute, Faculty of Life Sciences, Humboldt University of Berlin, Germany

17 Email addresses:

18 Eileen Kröber: ekroeber@mpi-bremen.de, Sonja Wende: Sonja.Wende@zalf.de, Saranya

19 Kanukollu: Saranya.Kanukollu@zalf.de, Caroline Buchen-Tschiskale:

20 caroline.buchen@thuenen.de, Ludovic Besaury: ludovic.besaury@univ-reims.fr, Frank

21 Keppler: frank.keppler@geow.uni-heidelberg.de, Stéphane Vuilleumier:

22 vuilleumier@unistra.fr, Steffen Kolb: Steffen.Kolb@zalf.de, Françoise Bringel:

$23 \quad$ francoise.bringel@unistra.fr

25 Corresponding authors: Eileen Kröber (ekroeber@mpi-bremen.de) and Françoise Bringel

26 (francoise.bringel@unistra.fr) 
Abstract (181 words)

Background: Chloromethane $\left(\mathrm{CH}_{3} \mathrm{Cl}\right)$ is the most abundant chlorinated volatile organic compound in the atmosphere and contributes to stratospheric ozone depletion. $\mathrm{CH}_{3} \mathrm{Cl}$ has mainly natural sources such as emissions from vegetation. In particular, ferns have been recognized as strong emitters. Mitigation of $\mathrm{CH}_{3} \mathrm{Cl}$ to the atmosphere by methylotrophic bacteria, a global sink for this compound, is likely underestimated and remains poorly characterized.

Results and Conclusions: We investigated chloromethane-degrading taxa associated with intact and living tree fern plants of the species Cyathea australis by stable isotope probing (SIP) with ${ }^{13} \mathrm{C}$-labelled $\mathrm{CH}_{3} \mathrm{Cl}$ combined with metagenomic DNA sequencing. Metagenome assembled genomes (MAGs) related to Methylobacterium and Friedmanniella were identified as being involved in the degradation of $\mathrm{CH}_{3} \mathrm{Cl}$ in the phyllosphere, i.e., the aerial parts of the tree fern, while a MAG related to Sorangium was linked to $\mathrm{CH}_{3} \mathrm{Cl}$ degradation in the fern rhizosphere. The only known metabolic pathway for $\mathrm{CH}_{3} \mathrm{Cl}$ degradation, via a methyltransferase system including the gene cmuA, was not detected in metagenomes or MAGs identified by SIP. Hence, a yet uncharacterised methylotrophic cmuA-independent pathway likely drives $\mathrm{CH}_{3} \mathrm{Cl}$ degradation in the investigated tree ferns.

Keywords: Chloromethane, Phyllosphere, Rhizosphere, Stable Isotope Probing (DNA-SIP), Metagenome-assembled genomes (MAGs), tree fern, one-carbon metabolism 
With an average global mixing ratio of $\sim 553 \pm 5$ pptv, an atmospheric lifetime of 0.9 years and an estimated global emission rate of 4 to $5 \mathrm{Tg}\left(1 \mathrm{Tg}=10^{12} \mathrm{~g}\right)$ per year $[1,2]$, chloromethane $\left(\mathrm{CH}_{3} \mathrm{Cl}\right.$, methyl chloride $)$ is one of the most abundant chlorinated volatile organic compounds (VOCs) in the Earth's atmosphere. Natural emissions of $\mathrm{CH}_{3} \mathrm{Cl}$ have been reported from grasslands [3-5], plants [6-11], salt marshes [12-14], peatlands [15], ventilated and waterlogged soil [16-18] and oceans [19]. Ferns are especially potent natural emitters of $\mathrm{CH}_{3} \mathrm{Cl}$ $[6,8,10]$.

The main sink for atmospheric $\mathrm{CH}_{3} \mathrm{Cl}$ is abiotic degradation by photochemically formed hydroxyl radicals [20], estimated at about 2.5 to $3.4 \mathrm{Tg}$ per year [21]. Microbial degradation in soils is another possible significant global sink of $\mathrm{CH}_{3} \mathrm{Cl}$ [22-25]. However, current estimates are highly uncertain, ranging from 0.1 to $1.6 \mathrm{Tg}$ per year $[21,23,26]$. Methylotrophic bacteria able to use $\mathrm{CH}_{3} \mathrm{Cl}$ as sole carbon and energy source for growth have been isolated from diverse environments, including soils [22, 24, 27], wastewater sludge [28-30], seawater [31, 32], and the phyllosphere (aerial parts of the plants) [33, 34]. The ubiquitous presence of such bacteria in soil and the phyllosphere implies that they play a more important role in mitigating the emission of $\mathrm{CH}_{3} \mathrm{Cl}$ to the atmosphere than previously thought [14, 35]. The bacterial chloromethane utilisation $(\mathrm{cmu})$ pathway was characterised in detail in Methylorubrum extorquens (previously Methylobacterium extorquens) strain CM4 [36, 37]. A corrinoid- and tetrahydrofolate $\left(\mathrm{H}_{4} \mathrm{~F}\right)$-dependent methyltransferase system, encoded by genes $c m u A$ and $c m u B$ [38, 39], respectively, effect dehalogenation of chloromethane. Since the cmuA gene is strongly conserved in $\mathrm{CH}_{3} \mathrm{Cl}$-degrading bacteria [33], it has been used as a metabolic marker gene to study the biodiversity of $\mathrm{CH}_{3} \mathrm{Cl}$-degrading microorganisms [22, 24, 40-42]. Phylogenetically diverse cmu-dependent chloromethane degraders have been isolated and belong to the genera Acetobacterium, Aminobacter, Hyphomicrobium, Leisingera, Pseudomonas, Methylobacterium/Methylorubrum, and Roseovarius [33].

82 However, the cmuA biomarker is seldom found in metagenomes [10, 25, 35]. In addition, cmu genes are absent in the genomes of some sequenced $\mathrm{CH}_{3} \mathrm{Cl}$ utilizers $[35,43]$ such as marine 
strains (Leisingera methylohalidivorans MB2) [32], which points towards the existence of yet uncharacterized pathways for $\mathrm{CH}_{3} \mathrm{Cl}$ degradation. All these microorganisms have in common that they have to adapt to several stresses in order to grow on $\mathrm{CH}_{3} \mathrm{Cl}$, for instance increased intracellular levels of protons and chloride, higher needs for the production of cofactors $\left(\mathrm{H}_{4} \mathrm{~F}\right.$ and cobalamin-related compounds) and the regulation of their metabolism for efficient $\mathrm{CH}_{3} \mathrm{Cl}$ utilisation $[35,37,44,45]$.

Chloromethane degradation associated with plants has been studied e.g. in Arabidopsis thaliana [11] and ferns such as Osmunda regalis, Cyathea cooperi and Dryopteris filix-mas [10]. The cmuA gene was found to be associated with living Arabidopsis thaliana plantlets [11], but $\mathrm{CH}_{3} \mathrm{Cl}$ degradation and microbial biodiversity were not assessed. In a subsequent study, both production and consumption of $\mathrm{CH}_{3} \mathrm{Cl}$ associated with three tropical fern species was investigated on cut-off plant material [10]. This may represent a stressful and potentially unphysiological condition, especially knowing that plants release VOCs after physical damage [46-48]. Therefore, cut-off plant material might release increased amounts of $\mathrm{CH}_{3} \mathrm{Cl}$ compared to intact plants. Microbial $16 \mathrm{~S}$ rRNA and $c m u A$ gene diversity analysis did not allow to correlate $\mathrm{CH}_{3} \mathrm{Cl}$ degradation with the microorganisms detected, nor could the corresponding metabolic pathways be identified [10]. In this study, we used an integrative experimental approach to identify the active $\mathrm{CH}_{3} \mathrm{Cl}$ degrading members of microbiota associated with rhizospheric soil and the phyllosphere of intact tree ferns known to produce $\mathrm{CH}_{3} \mathrm{Cl}$ [10], by applying a combination of DNA stable isotope probing (DNA-SIP) and metagenomics $[49,50]$ under conditions closely matching the native environment.

\section{Material and Methods}

Tree ferns, gas-tight plant-growth chambers and labelling of transplanted plants Tree ferns (Cyathea australis) with a shoot height of about $25 \mathrm{~cm}$ were obtained from a

110 commercial supplier (A L'ombre Des Figuiers, Combrit, France). Plants were grown in

111 Müncheberg Germany, and adapted to the local climate for three months before starting the 
112 DNA-SIP experiment on August $17^{\text {th }} 2017$. Incubations were carried out in gas-tight plant-

113 growth acryl-glass chambers (height of $120 \mathrm{~cm}$, volume of $\sim 85 \mathrm{~L}$ ) specifically manufactured

114 for the experiments (Reli Kunststoffe, Erkner, Germany). Chambers were fitted with ports 115 capped with air-tight butyl rubber stoppers (Merck Millipore Corporation, Darmstadt, Germany)

116 for injection of $\mathrm{CH}_{3} \mathrm{Cl}$ (Supplementary Figure 1A). In addition, ventilators were installed inside

117 the chambers to ensure an even distribution of gas throughout the chamber. Gas-tightness

118 was tested by injecting $\mathrm{CO}_{2}$ into each chamber and measuring the concentration over time

119 with $\mathrm{CO}_{2}$ loggers (data not shown). Since the aim of the experiment was to label $\mathrm{CH}_{3} \mathrm{Cl}-$

120 degrading microorganisms associated with fern plants, the side walls of the chambers were

121 covered with aluminium foil (Supplementary Figure 1B) to reduce photosynthesis and thus

122 microbial $\mathrm{CO}_{2}$ consumption during the labelling period. Nonetheless, some light still entered

123 the chambers through the transparent lid.

124 At the start of the experiment, a tree fern plant was placed in each of the six plant growth chambers (Supplementary Figure 1B). The tree fern plants were incubated with either ${ }^{13} \mathrm{C}$ -

126 labelled $\mathrm{CH}_{3} \mathrm{Cl}$ (Campro Scientific $\mathrm{GmbH}$, Berlin, Germany; named hereafter $\left[{ }^{13} \mathrm{C}\right]-\mathrm{CH}_{3} \mathrm{Cl}$ ) or 127 with $\mathrm{CH}_{3} \mathrm{Cl}$ at natural abundance $(99 \%$, Linde $\mathrm{GmbH}$, Pullach, Germany; named hereafter $\left.128\left[{ }^{12} \mathrm{C}\right]-\mathrm{CH}_{3} \mathrm{Cl}\right)$. Each labelling period lasted for about 6 hours during daylight, with plant growth 129 chambers opened and ventilated overnight until the next round of labelling took place at the 130 next day. At the start of the labelling experiment (August $\left.17^{\text {th }}\right), 20 \mathrm{~mL} \mathrm{CH}{ }_{3} \mathrm{Cl}\left(\left[{ }^{13} \mathrm{C}\right]-\mathrm{CH}_{3} \mathrm{Cl}\right.$ or $\left.131\left[{ }^{12} \mathrm{C}\right]-\mathrm{CH}_{3} \mathrm{Cl}\right)$ was added to the chambers, so that the initial mixing ration in the chamber was $132 \sim 200 \mathrm{ppm}$. Chambers were closed and ventilation was turned on. For the following 18 days, $13310 \mathrm{~mL}$ of $\mathrm{CH}_{3} \mathrm{Cl}\left(\left[{ }^{13} \mathrm{C}\right]-\mathrm{CH}_{3} \mathrm{Cl}\right.$ or $\left.\left[{ }^{12} \mathrm{C}\right]-\mathrm{CH}_{3} \mathrm{Cl}\right)$ was added every day, providing an initial mixing 134 ration in the chambers of $\sim 100 \mathrm{ppm}$. Gas samples were taken at the start of the incubation 135 period, after 2 and 4 hours and at the end of the incubation period with gas-tight syringes and 136 stored in $3 \mathrm{~mL}$, pre-evacuated Exetainers (Labco Limited, England) for further analysis by gas 137 chromatography combined with single quadrupole mass spectrometry (GC MS). ${ }^{13} \mathrm{C}$-labelling $138 \quad\left[{ }^{13} \mathrm{C}\right]-\mathrm{CH}_{3} \mathrm{Cl}$ and $\left[{ }^{12} \mathrm{C}\right]-\mathrm{CH}_{3} \mathrm{Cl}$ was carried out for 19 days. Soil humidity and salinity in the fern 139 soil was monitored throughout the experiment (data not shown). 
141 Chloromethane was measured in headspace gas by injecting $100 \mu \mathrm{L}$ of a headspace gas 142 sample into a ISQ ${ }^{\mathrm{TM}}$ Quadrupole GC MS System using a TRACE ${ }^{\mathrm{TM}}$ Ultra gas chromatograph 143 (Thermo Fisher Scientific, USA) fitted with a $60 \mathrm{~m}, 0.32 \mathrm{~mm}$ GS-GasPro capillary column 144 (Agilent Technologies, California, USA) with helium as the carrier gas (constant column flow rate, $1.5 \mathrm{~mL} \mathrm{~min}-1)$. Headspace gas samples $(100 \mu \mathrm{L})$ were injected into the column with a temperature ramp from $40^{\circ} \mathrm{C}$ to $200^{\circ} \mathrm{C}\left(15^{\circ} \mathrm{C}\right.$ increase $\left.\mathrm{min}^{-1}\right)$. High-throughput measurements were carried out with a MultiPurpose autosampler MPS (Gerstel Inc., USA). Chromatograms were analysed with Openchrome ${ }^{\circledR}$ (Lablicate $\mathrm{GmbH}$, Germany). $\mathrm{CH}_{3} \mathrm{Cl}$ concentrations were calculated by regression analysis based on a five-point calibration curve.

Analysis of carbon mass fraction (C \%) and differential stable carbon isotope ratio $\left(\delta^{13} \mathrm{C}\right.$ value) From each pot, an aliquot of the plant biomass was sampled at the start of the experiment, after 4 days and at the end of the incubation period (after 19 days). Samples were dried for $24 \mathrm{~h}$ at $60^{\circ} \mathrm{C}$ and finely ground using a vibrating disc mill (RS200, Retsch, Germany). Stable isotope ratios $\left({ }^{13} \mathrm{C} /{ }^{12} \mathrm{C}\right)$ were determined using an Elemental Analyzer (EA) Flash $2000 \mathrm{HT}$ (Thermo Fisher Scientific, Bremen, Germany), coupled with a Delta V isotope ratio mass spectrometer (IRMS) via a ConFlo IV interface (Thermo Fisher Scientific, Bremen, Germany). Stable carbon isotope ratios $\left(\delta^{13} \mathrm{C}\right)$ are expressed in permil (\%o) relative to the international standard, as defined by the equation:

$$
\delta^{13} C=\frac{R_{\text {Sample- }} R_{\text {Reference }}}{R_{\text {Sample }}}
$$

161 where $R_{\text {Sample }}$ is the isotopic ratio $\left({ }^{13} \mathrm{C} /{ }^{12} \mathrm{C}\right)$ of the sample and $R_{\text {Reference }}$ is the known isotopic 162 ratio of the standard. $\delta{ }^{13} \mathrm{C}$ values were normalized to the international scale Vienna Pee Dee 163 Belemnite (VPDB) by analyses of the international standards USGS40 and USGS41 (L164 glutamic acid) within the sequence [51]. Precision, defined as the standard deviation $( \pm 1 \sigma)$ of 165 the laboratory control standard along the run was better than $\pm 0.2 \%$ for $C$. 
166 For calculation of the element mass fraction C (percentage, \%) of plant biomass, different

167 amounts of the laboratory standard (apple leaves, $\delta{ }^{13} \mathrm{C}=-27.11 \%$, $\mathrm{C}=48.12 \%$ ) were

168 analysed and the linear regression between peak area and sample weight was used to

169 calculate the $C(\%)$. Precision, defined as the standard deviation $( \pm 1 \sigma)$ of the laboratory control

170 standard along the runs was better than $\pm 0.5 \%$ for $\mathrm{C}$.

172 Sample collection, DNA extraction and processing of DNA-SIP samples

173 After labelling, phyllosphere and rhizosphere soil samples of Cyathea australis plants were

174 collected as follows. For the phyllosphere, leaf wash (LW) and leaf (L) samples were collected.

175 Leaf wash samples were prepared as previously described [52], using $5 \mathrm{~g}$ of leaves and

176 collecting the leaf surface communities on a $0.22 \mu \mathrm{m}$ Durapore ${ }^{\circledR}$ membrane filter (Merck

177 Millipore Corporation, Darmstadt, Germany), and therefore comprised mainly epiphytes. Leaf

178 samples were cut off from the plants without washing using sterile razor blades, and hence

179 included epi- and endophytes. For the rhizosphere, $\sim 20 \mathrm{~g}$ of soil (S) samples were collected

180 near the roots (ectorhizosphere).

181 DNA extraction was carried out using the FastDNA ${ }^{T M}$ Spin Kit for Soil (MP Bio Science Ltd.,

182 Derby, UK) following the manufacturer's instructions. ${ }^{13} \mathrm{C}$-labelled heavy DNA was separated

183 from unlabelled light ${ }^{12} \mathrm{C}-\mathrm{DNA}$ using cesium chloride density gradient ultracentrifugation, as

184 described previously [53]. Density gradient formation across 12 fractions (250 $\mu \mathrm{L}$ each) was

185 confirmed by measuring refractive indexes using a digital refractometer (Reichert AR2000).

186 To identify ${ }^{13} \mathrm{C}$-DNA and ${ }^{12} \mathrm{C}-\mathrm{DNA}$ 'heavy' and 'light' fractions, respectively, and hence labelled

187 microorganisms, DNAs of all SIP fractions were first PCR-amplified. Primers 799F labelled at

188 the 5'-end with 6-carboxyfluorescein (6-FAM) and 1193r were used to amplify 16S rRNA gene

189 DNA fragments of $500 \mathrm{bp}$ [54]. For profiling of the bacterial communities present in the different

190 SIP fractions, terminal restriction fragment length polymorphism (T-RFLP) was used as

191 described [55], with normalization of T-RFLP profiles [56].

192

193 DNA barcoding for taxonomical identification and definition of the ${ }^{13} \mathrm{C}$-labelled OTUs 
194 Bacterial composition in $\left[{ }^{13} \mathrm{C}\right]-\mathrm{CH}_{3} \mathrm{Cl}$ and $\left[{ }^{12} \mathrm{C}\right]-\mathrm{CH}_{3} \mathrm{Cl}$ 'heavy' and 'light' fractions was

195 determined by amplicon sequencing using the primer set 5'-AACMGGATTAGATACCCKG-3',

196 5'- ACGCATCCCCACCTTCCTC-3' targeting the V5 and V7 hypervariable regions of the 197 bacterial 16S rRNA gene. Amplicon sequencing was performed on an Illumina Miseq platform 198 by GenoScreen (Lille, France). Amplicon reads were analysed using the QIIME pipeline [57] 199 and singletons and chimeras were removed using USEARCH v7 [58] and UCHIME [59].

200 Labelled OTUs were defined according to four criteria (adapted from [41]): 1) the relative 201 abundance of the OTU in the 'heavy' DNA fraction of the ${ }^{13} \mathrm{C}$-labelled microcosm was higher 202 than in the 'heavy' DNA fraction of the corresponding ${ }^{12} \mathrm{C}$-labelled microcosm; (2) the relative 203 abundance of the OTU was higher in the 'heavy' DNA fraction than in the 'light' fraction of the

$204{ }^{13}$ C-labelled microcosm; (3) the relative abundance of the OTU in the 'heavy' DNA fraction of 205 the ${ }^{13} \mathrm{C}$-labelled microcosm was $\geq 0.015 \%$, and $(4)$ the relative abundance difference of the 206 OTU between 'heavy' and 'light' DNA fractions was $\geq 0.005 \%$ and higher in the ${ }^{13} \mathrm{C}$-labelled 207 treatment than in the corresponding unlabelled control treatment.

\section{Metagenomics and bioinformatics}

210 Metagenomic sequencing was carried out using 'heavy' DNA fractions of $\left[{ }^{13} \mathrm{C}\right]-\mathrm{CH}_{3} \mathrm{Cl}-$ 211 amended fern samples combined from three biological replicates. The ${ }^{13} \mathrm{C}$-labelled heavy 212 fraction of leaf (L), leaf wash (LW) and soil (S) samples were sequenced on a HighSeq 213 platform and data was filtered and quality trimmed by GenoScreen (Lille, France). Processed

214 reads were assembled with MEGAHIT v.1.2.9 [60] with default options and additional 215 parameter "--presets meta-large", that sets a k-mer list from 27 to 127 in steps of 10 . An 216 additional co-assembly of leaf and leaf wash metagenomes was performed with the same 217 parameters, to improve recovery of low abundant species.

218 Binning was carried out using a combination of CONCOCT v1.1.0 [61], MetaBAT2 v2.12.1 219 [62] and MaxBin2 [63] under default parameters. For binning with CONCOCT and MetaBAT2 220 reads were first mapped to the assemblies using bowtie2 v2.3.5.1 [64] with the parameters "221 -sensitive-local --threads 80 --seed 100 --maxins 1000". Mapping results were used to 
generate depth files. For binning with MaxBin2 the binning module of MetaWRAP v1.2.1 [65] was used. The MetaWRAP bin_refinement module was used to consolidate binning results from MetaBAT2, MaxBin2 and CONCOCT into a final set of bins. Quality of the bins was estimated using CheckM v1.1.2 [66]. Bins with a reported completeness $>70 \%$ and contamination $<10 \%$ were selected as MAGs (Metagenome-Assembled Genomes) for further analysis (Supplementary Table S1). MAGs were annotated with RAST-tk [67] and the closest taxon was used for initial taxonomic classification. Identified proteins for MAGs were downloaded as 'faa-files' from RAST and used to place MAGs in a tree with 2850 references using the CVTree3 Web Server [68]. The deduced tree was visualized at $\mathrm{K}=6$ using the Interactive Tree of Life $\vee 5.5 .1$ [69], and used to select reference genomes for genome comparisons. The closest references around each MAG cluster were included in a pruned tree.

234 Closely related reference genomes were chosen for selected MAGs. PhyloPhIAn 3.0 [70] was run with "--diversity low" to identify common marker genes and construct a concatenated multiple sequence alignment (MSA) between MAGs and references. Maximum-likelihood trees were constructed with MEGAX [71] from MSAs using the $J T T+G+\mid$ model with 500 bootstrap replications. ANI values between MAGs and reference genomes were calculated with fastANI [72] v1.3 with "--fragLen 1500". AAI values were calculated with the CompareM v1.1.2 AAI workflow (aai_wf) (https://github.com/dparks1134/CompareM), where homology was defined as $>30 \%$ identity and $>70 \%$ alignment length. MAGs and metagenomes were screened for the presence of the chloromethane utilisation gene (cmuA) using BLAST [73], and prokka [74] under default settings, respectively. ShortBRED (version 0.9.3) [75] was used

244 to identify cmuA in unassembled metagenomic reads. MAGs were submitted to the MicroScope platform $[76,77]$ for annotation and analysis of genomic content and features using the Magnifying Genome $(\mathrm{MaGe})$ platform Web interface

247 (https://mage.genoscope.cns.fr/microscope/mage/). In addition, BLAST [73] and RAST [78] 248 were used to further compare MAG genetic content and assess potentials for $\mathrm{CH}_{3} \mathrm{Cl}$ utilization 249 by screening for functional marker genes involved in $\mathrm{CH}_{3} \mathrm{Cl}$ utilization, one-carbon 
metabolism, central metabolism, co-factor synthesis, transport systems, and stress response.

251 Enzymes that use or produce halides were detected using the BRENDA database available at www.brenda-enzymes.org, and adapted from [79]. This more in-depth MAG genetic content analysis was performed for six MAGs from the phyllosphere (LEAF and LEASFWASH) and rhizosphere (SOIL) named hereafter: 'Fern $\mathrm{CH}_{3} \mathrm{Cl}$ SIP LEAF bin s3', 'Fern $\mathrm{CH}_{3} \mathrm{CI}$ SIP LEAF bin co1', 'Fern $\mathrm{CH}_{3} \mathrm{Cl}$ SIP LEAF bin $\mathrm{co3}^{\prime}$, 'Fern $\mathrm{CH}_{3} \mathrm{Cl}$ SIP LEAFWASH bin co7', 'Fern $\mathrm{CH}_{3} \mathrm{Cl}$ SIP SOIL bin s1', and 'Fern $\mathrm{CH}_{3} \mathrm{CI}$ SIP SOIL bin s7'.

Comparative genome analyses

Genome comparisons within the genus Methylobacterium and the closely related clade Methylorubrum to determine pan, core and dispensable genes and singletons (unique genes) was carried out using EDGAR v2.0 [80] as described previously [81]. The $\mathrm{MAG}$ Fern $\mathrm{CH}_{3} \mathrm{Cl}$ SIP LEAF bin s3 was used as a reference and strains of Methylobacterium (including Methylorubrum) used for this analysis are listed in Supplementary Table S2.

Accession numbers for datasets

Read data of the tree fern metagenomes have been submitted to the National Center for Biotechnology Information (NCBI) under the BioProject number PRJNA659413. The metagenome assembled genomes for 'Fern $\mathrm{CH}_{3} \mathrm{Cl}$ SIP LEAF bin s3', 'Fern $\mathrm{CH}_{3} \mathrm{Cl}$ SIP LEAF bin co1', 'Fern $\mathrm{CH}_{3} \mathrm{Cl}$ SIP LEAF bin co3', 'Fern $\mathrm{CH}_{3} \mathrm{Cl}$ SIP LEAFWASH bin co7', 'Fern $\mathrm{CH}_{3} \mathrm{Cl}$ SIP SOIL bin s1', and 'Fern $\mathrm{CH}_{3} \mathrm{Cl}$ SIP SOIL bin s7', can be found in MaGe

271 (https://mage.genoscope.cns.fr/microscope/home/index.php) and under the same BioProject with BioSample Accession numbers SAMN17394138, SAMN17394139, SAMN17394140, SAMN17394141, SAMN17394142, SAMN17394143, respectively.

\section{Results and discussion}

276 The tree fern $\underline{\text { Cyathea australis }}$ and its associated microbiome is capable of $\mathrm{CH}_{3} \mathrm{Cl}$ 
278 As previously shown, cut-off leaves from the tree fern Cyathea australis are capable of $\mathrm{CH}_{3} \mathrm{Cl}$

279 degradation [10]. However, it has not been investigated if intact plants behave in the same 280 way and degrade $\mathrm{CH}_{3} \mathrm{Cl}$. In addition, the active members of the tree fern-associated 281 microbiota possibly involved in $\mathrm{CH}_{3} \mathrm{Cl}$ degradation has not been studied. Therefore, tree ferns 282 were incubated with either $\left[{ }^{13} \mathrm{C}\right]-\mathrm{CH}_{3} \mathrm{Cl}$ or $\left[{ }^{12} \mathrm{C}\right]-\mathrm{CH} \mathrm{Cl}_{3}$ and $\mathrm{CH}_{3} \mathrm{Cl}$ concentrations were monitored over a time period of 19 days. On the first day of incubation, $200 \mathrm{ppm}\left[{ }^{13} \mathrm{C}\right]-\mathrm{CH}_{3} \mathrm{Cl}$ or $\left[{ }^{12} \mathrm{C}\right]-\mathrm{CH}_{3} \mathrm{Cl}$ was added to the incubation chambers (Supplementary Figure 2). Rapid consumption was evident, and most likely due to adsorption to the soil-plant-interface. However, in the following 18 days, steady degradation of $\mathrm{CH}_{3} \mathrm{Cl}$ was observed following daily $\mathrm{CH}_{3} \mathrm{Cl}$ addition, especially from day 12 onwards, with an average $\mathrm{CH}_{3} \mathrm{Cl}$ consumption of 7-15 ppm d $\mathrm{d}^{-1}$ (Supplementary Figure 2). In order to investigate if the ${ }^{13} \mathrm{C}$ was incorporated by the plant or by microorganisms living on the surface of plant leaves (epiphytes), $\delta^{13} \mathrm{C}$ values of bulk leaves were determined using EA/IRMS. Stable carbon isotope values (Supplementary Figure 3) showed an increase in the $\left[{ }^{13} \mathrm{C}\right]-\mathrm{CH}_{3} \mathrm{Cl}$ incubated samples from the start of the experiment $\left({ }^{13} \mathrm{C} \mathrm{T}_{0}\right.$, about $-29 \%$ ) to the end of the experiment ( $\mathrm{T}_{\text {end }}$, about $-7.5 \%$ ) in the incubated ferns 1 and 3 , demonstrating an incorporation of ${ }^{13} \mathrm{C}$. Washed leaves $\left({ }^{13} \mathrm{C} \mathrm{T}_{\text {end }}\right.$ washed) showed much lower deviations of $\delta^{13} \mathrm{C}$ values (Supplementary Figure 3; fern 1 and 3 , about $-24 \%$ ), indicating incorporation of ${ }^{13} \mathrm{C}$ mainly by the microorganisms living on leaf surfaces. Therefore, we have shown here that intact living tree fern plants of the species Cyathea australis and their associated microbiota are capable of $\mathrm{CH}_{3} \mathrm{Cl}$ degradation and that the microorganisms most likely play a more important role in the degradation of this chlorinated volatile organic compound than previously anticipated.

Methylobacterium is an abundant genus with $\mathrm{CH}_{3} \mathrm{Cl}$-degrading representatives in the fern phyllosphere, and active chloromethane-utilizing bacteria differ in the fern phyllosphere and rhizosphere

304 In order to identify ${ }^{13} \mathrm{C}$-labelled microorganisms and hence, the microorganisms most likely responsible for $\mathrm{CH}_{3} \mathrm{Cl}$ degradation in the fern phyllosphere, 'heavy' and 'light' DNA fractions 
306 were identified using T-RFLP (showing an enrichment of certain TRFs in the ${ }^{13} \mathrm{C}$-'heavy'

307 fraction compared to the ${ }^{12} \mathrm{C}$-'heavy' and ${ }^{13} \mathrm{C}$-'light' fractions; data not shown), and the 308 corresponding fractions were used for 16S rRNA amplicon sequencing.

309 Methylobacterium was identified as the most abundant ${ }^{13} \mathrm{C}$-labelled genus in the phyllosphere 310 (leaf) of Cyathea australis (Figure 1). It is well-established that Methylobacterium are abundant 311 in the phyllosphere of a variety of plants [83] including Arabidopsis thaliana [11, 84-86], 312 soybean [86-88], clover [86], cotton [87], maize [87], sunflower [87] and rice [89], and that 313 representatives of the genus Methylobacterium can utilize $\mathrm{CH}_{3} \mathrm{Cl}$ via the chloromethane 314 utilization pathway $(\mathrm{cmu})$ [33]. Whereas Methylobacterium has been identified previously in 315 the phyllosphere of three different $\mathrm{CH}_{3} \mathrm{Cl}$-producing or $\mathrm{CH}_{3} \mathrm{Cl}$-degrading ferns, Osmunda 316 regalis, Cyathea cooperi and Dryopteris filix-mas [10], a correlation between in planta $\mathrm{CH}_{3} \mathrm{Cl}$ 317 degradation and the microorganisms detected could not be demonstrated in these previous 318 studies.

319 In the fern phyllosphere (leaf and leaf wash samples), other ${ }^{13} \mathrm{C}$-labelled microorganisms than 320 Methylobacterium-related, included members of families Pseudomonadaceae (leaf), 321 Propionibacteriaceae, and Solirubrobacteraceae (leaf wash), among others (Figure 1). 322 Pseudomonadaceae were detected in a $\mathrm{CH}_{3} \mathrm{Cl}$-degrading mixed culture [33], but their role in $323 \mathrm{CH}_{3} \mathrm{Cl}$ degradation was not assessed. Among those, members of the family 324 Pseudomonadaceae are well known colonizers of the phyllosphere of a variety of plants, such 325 as soybean, colver, rice, A. thaliana [90, 91], grapevine [92], maize [93] and lettuce [94], to 326 name only a few. Pseudomonadaceae have been associated with ferns involved in $\mathrm{CH}_{3} \mathrm{Cl}$ 327 production and consumption [10], and some isolates of the genus Pseudomonas capable of $328 \mathrm{CH}_{3} \mathrm{Cl}$ degradation have been reported [10,30,33]. In contrast, representatives of 329 Propionibacteriaceae and Solirubrobacteraceae capable of $\mathrm{CH}_{3} \mathrm{Cl}$ degradation have not been 330 described so far. Propionibacteriaceae closely related Friedmaniella members have been 331 found in the phyllosphere of magnolia trees [95], hemlock plants [96], in grasses such as 332 Arrhenatherum elatius [97], in Baccharis dracunculifolia [98] and in hardwood forest trees such 333 as maple, oak and lime [99]. Bacteria of the family Solirubrobacteraceae are strictly aerobic 
and chemoorganotrophic [100], and have been identified in the phyllosphere of Baccharis dracunculifolia [98], in grasses such as Arrhenatherum elatius [97], and in olive trees [101].

336 Compared to the phyllosphere, different taxa were enriched in the ${ }^{13} \mathrm{C}$-'heavy' DNA of

337 rhizosphere samples (Figure 1), e.g. from Xanthobacteraceae and Myxococcales, but a 338 potential association of these families with degradation of $\mathrm{CH}_{3} \mathrm{Cl}$ has not yet been reported.

339 Xanthobacteraceae were enriched in a $\mathrm{CH}_{3} \mathrm{Cl}$-incubated forest soil in a previous study [25],

340 but also detected in the phyllosphere of grassland plants [97], tomatoes [102], and hay [103].

341 Worthy of note in the context of chloromethane utilisation, Xanthobacter autotrophicus, a

342 member of family Xanthobacteraceae, is a methylotrophic organism capable of growing with 343 methanol $[104,105]$. Myxococcales were detected in e.g. the phyllosphere of magnolia trees 344 [95], apple trees [106] and rocket [107], and also present in the core microbiome of the phyllosphere of five different trees species in a temperate forest in Quebec [108]. Thus, the living fern tree is host to a variety of potential $\mathrm{CH}_{3} \mathrm{Cl}$-utilisers, of which most differ from previously characterized representatives.

Tree fern MAGs from $\left[{ }^{13} \mathrm{C}\right]-\mathrm{CH}_{3} \mathrm{Cl}$ DNA are closely related to Methylobacterium, Friedmanniella and Sorangium

Metagenomics of $\left[{ }^{13} \mathrm{C}\right]-\mathrm{CH}_{3} \mathrm{Cl}$ labelled fern phyllosphere and rhizosphere samples was carried out to complement and expand the $16 \mathrm{~S}$ rRNA amplicon sequencing analysis. Of the 34 MAGs, three carried 16S rRNA-encoding genes (Supplemental Table S1). To further elucidate the phylogeny of the $\left[{ }^{13} \mathrm{C}\right]-\mathrm{CH}_{3} \mathrm{Cl}$ labelled microorganisms, phylogenetic trees were calculated using the MAGs 'Fern $\mathrm{CH}_{3} \mathrm{Cl}$ SIP LEAF bin co1', 'Fern $\mathrm{CH}_{3} \mathrm{Cl}$ SIP LEAF bin s3', 'Fern $\mathrm{CH}_{3} \mathrm{Cl}$ SIP LEAF bin co3', 'Fern $\mathrm{CH}_{3} \mathrm{Cl}$ SIP LEAFWASH bin co7', 'Fern $\mathrm{CH}_{3} \mathrm{CI}$ SIP SOIL bin s1' and 'Fern $\mathrm{CH}_{3} \mathrm{Cl}$ SIP SOIL bin s7' (Figure 2). MAG's 'Fern $\mathrm{CH}_{3} \mathrm{Cl}$ SIP LEAF bin co1' and 'Fern $\mathrm{CH}_{3} \mathrm{CI}$ SIP LEAF bin s3' clustered within the genus Methylobacterium (Figure 2A). The MAG 'Fern $\mathrm{CH}_{3} \mathrm{Cl}$ SIP LEAF bin s3' was more closely related to Methylobacterium phyllosphaerae CBMB27, M. phyllostachyos BL47, M. pseudosasicola BL36 and M. oryzae 
362 'Fern $\mathrm{CH}_{3} \mathrm{Cl}$ SIP LEAF bin co3' and 'Fern $\mathrm{CH}_{3} \mathrm{Cl}$ SIP LEAFWASH bin co7' clustered more

363 closely to the genus Friedmaniella of the family Propionibacteriaceae (Figure 2B). Bins 'Fern

$364 \mathrm{CH}_{3} \mathrm{Cl}$ SIP SOIL bin s1' and 'Fern $\mathrm{CH}_{3} \mathrm{Cl}$ SIP SOIL bin s7' showed closest but more distant 365 similarity with Sorangium (Figure 2C), possibly representing a new genus within the order Myxococcales. Taken together, the phylogeny based on MAGs supported the findings on ${ }^{13} \mathrm{C}$ labelled OTUs based on the results from 16S rRNA amplicon sequencing.

cmuA genes are not present in metagenomes and MAGs

370 The cmu pathway is the only characterized pathway for utilisation of $\mathrm{CH}_{3} \mathrm{Cl}$ [35]. Of the $\mathrm{cmuA}$ and $c m u B$-encoded methyltransferases of chloromethane dehalogenase, the $c m u A$ gene is the most conserved and has been frequently used as the cmu pathway gene marker [109]. The MAGs and metagenomes were screened for the presence of $c m u A$. On the basis of BLAST searches and prokka annotations, no cmuA homologs could be identified in metagenome-assembled genomes. Using shortBRED, unassembled short metagenomic reads were screened for the presence of $c m u A$. Unlike reference genes for methanol oxidation (xoxF and $m x a F$ ) which were detected in leaf, leafwash and soil samples (data not shown), the cmuA gene was not detectable in leafwash and leaf samples. In soil samples, only seldom and very short sequences (between 8 and 15 amino acids) matched to a small fragment of CmuA (data not shown) when using shortBRED. This lack of evidence for the presence of cmuA suggests that $\mathrm{CH}_{3} \mathrm{Cl}$ degradation in tree fern samples occur by other routes.

$\mathrm{CH}_{3} \mathrm{Cl}$ in tree ferns is degraded by yet unidentified chloromethane utilisation pathways

384 The genome sequences retrieved from ${ }^{13} \mathrm{C}$-labelled MAGs offered an opportunity to investigate the metabolic traits of these bacteria. Metabolic reconstruction was performed with the two MAGs related to Methylobacterium ('Fern $\mathrm{CH}_{3} \mathrm{Cl}$ SIP LEAF bin co1' and 'Fern $\mathrm{CH}_{3} \mathrm{Cl}$ SIP LEAF bin s3'), one of the bins related to Friedmaniella ('Fern $\mathrm{CH}_{3} \mathrm{CI}$ SIP LEAF bin co3') and one of the bins related to Sorangium ('Fern $\mathrm{CH}_{3} \mathrm{CI}$ SIP SOIL bin s1'). 
389 Beyond the already noted lack of $c m u A$, analysis of these MAGs also revealed the absence 390 of the other essential genes (cmuB $[36]$ and metF2 $[45,110])$ of the cmu pathway (Figure 3), 391 confirming that $\mathrm{CH}_{3} \mathrm{Cl}$-degrading bacteria on tree ferns may use other pathways for $\mathrm{CH}_{3} \mathrm{Cl}$ 392 utilization. In contrast, genes folD encoding the bifunctional enzyme methylene- $\mathrm{H}_{4} \mathrm{~F}$ 393 dehydrogenase/methenyl- $\mathrm{H}_{4} \mathrm{~F}$-cyclohydrolase and purU encoding the formyl- $\mathrm{H}_{4} \mathrm{~F}$ deformylase 394 which allow downstream processing of one-carbon units derived from $\mathrm{CH}_{3} \mathrm{Cl}$ [36] were 395 detected in three and two of the four MAGs, respectively (Figure 3). Similarly, other genes 396 associated with one-carbon metabolism including $m t d A$ for methylene- $\mathrm{H}_{4} \mathrm{~F}$ dehydrogenase, 397 fch for methenyl- $\mathrm{H}_{4} \mathrm{~F}$ cyclohydrolase, and $\mathrm{ftfL}$ for formate- $\mathrm{H}_{4} \mathrm{~F}$ ligase were also detected in 398 Methylobacterium-related MAGs, as expected [111-113] (Figure 3, Supplementary Table S3). 399 In many methylotrophs, methylene- $\mathrm{H}_{4} \mathrm{~F}$ is the entry point for carbon assimilation through the 400 ethylmalonyl-CoA pathway (EMCP) cycle, and most genes were detected in two out of four 401 MAGs, and/or the glycine cleavage system pathway (GCP) with genes detected in the two 402 MAGs lacking the EMCP cycle (Figure 3, Supplementary Table S3). Furthermore, the last step 403 in one-carbon compound reduction/oxidation is the conversion of formate to $\mathrm{CO}_{2}$ that involves 404 the fdh-encoded formate dehydrogenase found in the two MAGs related to Methylobacterium 405 and the MAG related to Friedmaniella. Thus, analysis of the MAGs obtained from heavy DNA 406 confirmed that they possess the genetic potential for one-carbon compound 407 reduction/oxidation, and also suggest that $\mathrm{H}_{4} \mathrm{~F}$ is a one-carbon-group carrier in all four MAGs 408 (Figure 3, Supplementary Table S3). While these data clearly suggest that methylene- $\mathrm{H}_{4} \mathrm{~F}$ is 409 also the entry point to central metabolism in tree fern MAGs from $\mathrm{CH}_{3} \mathrm{Cl}$ degradation, how this 410 is achieved by the corresponding strains remains unknown. Moreover, it is puzzling that MAGs 411 related to species not previously described as methylotrophs (e.g. Friedmaniellea and 412 Sorangium) and which are lacking reference genes for primary oxidation of one-carbon 413 compounds (Supplemental Table S3) were $\left[{ }^{13} \mathrm{C}\right]$-chloromethane labelled. One hypothesis is 414 that genes encoding methylotrophic genes were excluded from the assembly, for instance if 415 plasmid-borne, associated to mobile elements or if present on genomic islands. Another 
416 possibility is that these MAGs correspond to microorganisms that harbour so far

417 uncharacterized genes for methyltrophic growth.

418 The MAG more closely related to Methylobacterium ('Fern $\mathrm{CH}_{3} \mathrm{CI}$ SIP LEAF bin s3') harbours

419 in addition the genes for the one-carbon compound oxidation pathway via 420 tetrahydromethanopterin $\left(\mathrm{H}_{4} \mathrm{MPT}\right)$. One explanation for this phenomenon might be the 421 incompleteness of MAGs. The last step of the one-carbon compound oxidation pathway, the 422 oxidation of formate to carbon dioxide, is mediated by the formate dehydrogenase ( $f d h)$, which 423 was detected in three out of the four MAGs. The gene encoding for the formaldehyde424 activating enzyme (fae), which catalyses the reduction of formaldehyde with $\mathrm{H}_{4} \mathrm{MPT}$ was only 425 detected in the MAG more closely related to Methylobacterium ('Fern $\mathrm{CH}_{3} \mathrm{Cl}$ SIP LEAF bin 426 s3') suggesting that the other three MAGs lack the H$_{4}$ MPT pathway for formaldehyde oxidation 427 (Figure 3, Supplementary Table S3).

Gene content for halide metabolism in MAGs

430 Halide ions such as $\mathrm{Cl}^{-}, \mathrm{Br}^{-}, \mathrm{I}^{-}$are substrates, products or both for dehalogenases. 431 Dehalogenases can hydrolyse a broad range of haloalkanes to e.g. the corresponding 432 alcohols, and as a rule this will accompanied by the release of protons and halide ions. 433 Searches using the BRENDA database led to the detection of putative genes encoding 434 halogenases (3) and dehalogenases (40) in MAGs obtained from ${ }^{13} \mathrm{C}$-labelled DNA 435 (Supplemental Table S4), which may potentially be associated with dehalogenation of 436 chloromethane. Further experiments are needed to investigate this point.

438 Comparative genomics of Methylobacterium-related MAGs

439 Since Methylobacterium represents the best-investigated bacterial genus for utilisation of one440 carbon compounds, including $\mathrm{CH}_{3} \mathrm{Cl}$, an in depth-analysis of the two MAGs most closely 441 related to Methylobacterium was performed. Thus, Fern $\mathrm{CH}_{3} \mathrm{Cl}$ SIP LEAF bin c1 and Fern $442 \mathrm{CH}_{3} \mathrm{Cl}$ SIP LEAF bin s3 were compared with representative complete genomes of other 443 members of the genus Methylobacterium including Methylorubrum (Figure 4, Supplementary 
444 Table S2) to identify genes present in all strains (core genes), two or more strains (accessory

445 or dispensable genes), and only in one strain (singleton genes). According to pan-genome 446 analysis of 15 Methylobacterium genomes (including three Methylorubrum strains and two 447 MAGs from this study), a total of 25,534 genes were identified, of which $52.4 \%$ were singletons 448 (13,375 CDS), and only $2.5 \%$ were shared by all 15 Methylobacterium genomes (core 449 genome, 626 CDS; Figure 4a). An UpSet plot [114] shows the number of CDS in the core genome, the singletons but also the number of CDS shared by the different Methylobacterium genomes (including Methylorubrum, Figure 4b). These analyses confirmed the phylogeny of the phylogenetic tree (Figure 2A), i.e. it revealed a high similarity between Methylobacterium phyllosphaerae and Methylobacterium oryzae (392 uniquely shared CDS) and between Methylorubrum populi and Methylorubrum extorquens (233 uniquely shared CDS). Genes encoding for enzymes that use or produce halides (Supplementary Table S4) and are present in the two MAGs obtained in this work do not belong to the core genome shared by the 15 Methylobacterium strains (including Methylorubrum).

\section{Conclusions}

460 Chloromethane is massively produced by some tree ferns $[8,10]$, and these plants have therefore been suggested to be important emitters of this compound to the atmosphere [6]. However, microorganisms living in close association with these plants might substantially mitigate the emission of $\mathrm{CH}_{3} \mathrm{Cl}$ into the atmosphere. In this context, recent isotopic mass balances of atmospheric $\mathrm{CH}_{3} \mathrm{Cl}$ including isotopic analysis of carbon [115], hydrogen [116] and chlorine [117] point to large unidentified terrestrial sinks and sources of $\mathrm{CH}_{3} \mathrm{Cl}$. The present study reveals the complexity of $\mathrm{CH}_{3} \mathrm{Cl}$ associated processes occurring in tree ferns. In addition, the observed lag in the onset of $\mathrm{CH}_{3} \mathrm{Cl}$ degradation associated with tree ferns could also point to microbial adaptation. As such, we demonstrated that ${ }^{13} \mathrm{C}$-labelled $\mathrm{CH}_{3} \mathrm{Cl}$ is incorporated into DNA of microorganisms of the leaf surface of tree ferns, and not to plant biomass, since insignificant ${ }^{13} \mathrm{C}$ incorporation was found in washed leaves. Moreover, we identified key microorganisms involved in $\mathrm{CH}_{3} \mathrm{Cl}$ degradation in the phyllosphere and 
rhizosphere. These were closely related to Methylobacterium, Friedmanniella and Sorangium,

473 all known to be capable of inhabiting the phyllosphere. Of these genera however, only 474 Methylobacterium (including Methylorubrum, e.g. Methylorubrum extorquens strain CM4) 475 strains were previously described to be capable of $\mathrm{CH}_{3} \mathrm{Cl}$ degradation. Moreover, the canonical cmu-dependent $\mathrm{CH}_{3} \mathrm{Cl}$ degradation pathway could not be detected in the heavy DNA fraction obtained in ${ }^{13} \mathrm{C}-\mathrm{CH}_{3} \mathrm{Cl}$ incubations of tree ferns. These findings suggest that biodegradation pathways other than the $\mathrm{cmu}$ pathway were predominantly involved in degradation of $\mathrm{CH}_{3} \mathrm{Cl}$ in the investigated tree fern species Cyathea australis. Our study thus demonstrates that $\mathrm{CH}_{3} \mathrm{Cl}$ emissions from living plants is modified by microbial consumption by other bacteria than from the well-known genus Methylobacterium. For future studies, incubations under lower, environmentally observed concentrations ( 600 pptv), coupled with targeted proteomics and/or transcriptomics approaches, may help to identify as yet unidentified $\mathrm{CH}_{3} \mathrm{Cl}$ degradation pathways. Finally, the application of triple element isotope analysis [117] might provide clues on the global relevance of vegetation and their associated microbes in mitigating emissions of $\mathrm{CH}_{3} \mathrm{Cl}$ to the atmosphere.

Declarations

490

491 Ethics approval and consent to participate

492 Not applicable

\section{Consent for publication}

495 Not applicable

497 Availability of data and material

498 Read data of the tree fern metagenomes have been submitted to the National Center for 499 Biotechnology Information (NCBI) under the BioProject number PRJNA659413. The 
metagenome assembled genomes for 'Fern $\mathrm{CH}_{3} \mathrm{Cl}$ SIP LEAF bin s3', 'Fern $\mathrm{CH}_{3} \mathrm{Cl}$ SIP LEAF

501 bin co1', 'Fern $\mathrm{CH}_{3} \mathrm{Cl}$ SIP LEAF bin co3', 'Fern $\mathrm{CH}_{3} \mathrm{Cl}$ SIP LEAFWASH bin co7', 'Fern $\mathrm{CH}_{3} \mathrm{Cl}$

502 SIP SOIL bin s1', and 'Fern $\mathrm{CH}_{3} \mathrm{Cl}$ SIP SOIL bin s7', can be found under the same BioProject

503 with BioSample Accession numbers SAMN17394138, SAMN17394139, SAMN17394140,

504 SAMN17394141, SAMN17394142, SAMN17394143, respectively.

505

506 Competing interests

507 Not applicable

508

509 Funding: This study was supported with funding from the German Research Foundation

510 (DFG; 'Chlorofilter' grants KO 2912/10-1 and KE 884/10-1) and the French 'Agence Nationale

511 de la Recherche' (ANR; grant ANR-AA-14CE35-005-01) to the CHLOROFILTER project.

512

\section{Authors' contributions}

514 SK and FB conceived the research. EK, SW, FB analyzed the data. EK carried out the 515 experimental research. EK, FB, CBT, SK, SV, FK discussed experiments and interpreted the 516 results. The manuscript was written under the lead of EK and FB with contributions of all 517 authors.

519 Acknowledgments: EK gratefully acknowledges support through the DFG. FB acknowledges

520 the Bio-Informatic MicroScope platform at Evry (France) for annotation and comparative 521 analysis of MAGs. We also thank Marco Heyde for assistance during the experiments.

523 Supplementary Materials:

524 Supplementary Figure S1. Plant growth chamber setup.

525 Supplementary Figure S2. Monitoring of the SIP-incubation of ferns. 
526 Supplementary Figure S3. Analysis of carbon mass fraction (C \%) and differential stable

527 carbon isotope ratio $\left(\delta^{13} \mathrm{C}\right.$ value $)$ of fern leaves and washed leaf samples ( $T_{\text {end }}$ washed $)$ via 528 EA/IRMS.

529 Supplementary Table S1. List of metagenome-assembled genomes (MAGs).

530 Supplementary Table S2. List of Methylobacterium (including Methylorubrum) genomes used

531 for pan-genomics.

532 Supplementary Table S3. Methylotrophic pathway genes in labelled MAGs.

533 Supplementary Table S4. Enzymes potentially using or producing halides in labelled ${ }^{13} \mathrm{C}$ 534 MAGs.

535

536 Conflicts of Interest: The authors declare no conflict of interest.

537

538

539

540

541

542

543

544

545

546

547

548

549

550

551

552 
1. Keppler F, Harper D, Röckmann T, Moore R, Hamilton J: New insight into the atmospheric chloromethane budget gained using gained using. Atmospheric Chemistry and Physics 2005, 5.

2. Xiao X, Prinn RG, Fraser PJ, Simmonds PG, Weiss RF, O'Doherty S, Miller BR, Salameh PK, Harth CM, Krummel PB, et al: Optimal estimation of the surface fluxes of methyl chloride using a 3-D global chemical transport model. Atmospheric Chemistry and Physics 2010, 10.

3. Rhew RC: Sources and sinks of methyl bromide and methyl chloride in the tallgrass prairie: applying a stable isotope tracer technique over highly variable gross fluxes. Journal of Geophysical Research: Biogeosciences 2011, 116.

4. Rhew RC, Abel T: Measuring simultaneous production and consumption fluxes of methyl chloride and methyl bromide in annual temperate grasslands. Environmental science \& technology 2007, 41:7837-7843.

5. Teh YA, Rhew RC, Atwood A, Abel T: Water, temperature, and vegetation regulation of methyl chloride and methyl bromide fluxes from a shortgrass steppe ecosystem. Global change biology 2008, 14:77-91.

6. Yokouchi Y, Ikeda M, Inuzuka Y, Yukawa T: Strong emission of methyl chloride from tropical plants. Nature 2002, 416:163-165.

7. Hamilton JT, McRoberts WC, Keppler F, Kalin RM, Harper DB: Chloride methylation by plant pectin: an efficient environmentally significant process. Science 2003, 301:206-209.

8. Yokouchi Y, Takenaka A, Miyazaki Y, Kawamura K, Hiura T: Emission of methyl chloride from a fern growing in subtropical, temperate, and cool temperate climate zones. Journal of Geophysical Research: Biogeosciences 2015, 120:11421149.

9. Blei E, Hardacre CJ, Mills GP, Heal KV, Heal MR: Identification and quantification of methyl halide sources in a lowland tropical rainforest. Atmospheric Environment 2010, 44:1005-1010.

10. Jaeger N, Besaury L, Röhling AN, Koch F, Delort A-M, Gasc C, Greule M, Kolb S, Nadalig T, Peyret $\mathrm{P}$, et al: Chloromethane formation and degradation in the fern phyllosphere. Science of the Total Environment 2018, 634:1278-1287.

11. Ul Haque MF, Besaury L, Nadalig T, Bringel F, Mutterer J, Schaller H, Vuilleumier S: Correlated production and consumption of chloromethane in the Arabidopsis thaliana phyllosphere. Scientific reports 2017, 7:1-10.

12. Rhew RC, Miller BR, Weiss RF: Natural methyl bromide and methyl chloride emissions from coastal salt marshes. Nature 2000, 403:292-295.

13. Valtanen A, Solloch S, Hartikainen H, Michaelis W: Emissions of volatile halogenated compounds from a meadow in a coastal area of the Baltic Sea. Boreal Environment Research 2009, 14:915-931.

14. Keppler F, Röhling AN, Jaeger N, Schroll M, Hartmann SC, Greule M: Sources and sinks of chloromethane in a salt marsh ecosystem: constraints from concentration and stable isotope measurements of laboratory incubation experiments. Environmental Science: Processes \& Impacts 2020, 22:627-641.

15. Dimmer CH, Simmonds PG, Nickless G, Bassford MR: Biogenic fluxes of halomethanes from Irish peatland ecosystems. Atmospheric Environment 2001, 35:321-330. 
16. Keppler F, Eiden R, Niedan V, Pracht J, Schöler H: Halocarbons produced by natural oxidation processes during degradation of organic matter. Nature 2000 , 403:298-301.

17. Keppler F, Eiden R, Niedan V, Pracht J, Schöler H: Correction: Halocarbons produced by natural oxidation processes during degradation of organic matter. Nature 2001, 409:382-382.

18. Redeker K, Wang N-Y, Low J, McMillan A, Tyler S, Cicerone R: Emissions of methyl halides and methane from rice paddies. Science 2000, 290:966-969.

19. Moore RM, Groszko W, Niven SJ: Ocean atmosphere exchange of methyl chloride: Results from NW Atlantic and Pacific Ocean studies. Journal of Geophysical Research: Oceans 1996, 101:28529-28538.

20. Khalil M, Rasmussen R: Atmospheric methyl chloride. Atmospheric Environment 1999, 33:1305-1321.

21. Carpenter LJ, Reimann S, Burkholder JB, Clerbaux C, Hall BD, Hossaini R, Laube JC, Yvon-Lewis SA, Engel A, Montzka S: Update on ozone-depleting substances (ODSs) and other gases of interest to the Montreal protocol. Scientific Assessment of Ozone Depletion 2014:1.1-1.101.

22. McAnulla C, McDonald IR, Murrell JC: Methyl chloride utilising bacteria are ubiquitous in the natural environment. FEMS Microbiology Letters 2001, 201:151155.

23. Harper DB, Hamilton JT: The global cycles of the naturally-occurring monohalomethanes. In Natural Production of Organohalogen Compounds. Springer; 2003: $17-41$

24. Miller LG, Warner KL, Baesman SM, Oremland RS, McDonald IR, Radajewski S, Murrell JC: Degradation of methyl bromide and methyl chloride in soil microcosms: use of stable $C$ isotope fractionation and stable isotope probing to identify reactions and the responsible microorganisms. Geochimica et Cosmochimica Acta 2004, 68:3271-3283.

25. Jaeger N, Besaury L, Kröber E, Delort AM, Greule M, Lenhart K, Nadalig T, Vuilleumier S, Amato P, Kolb S, et al: Chloromethane degradation in soils: A combined microbial and two dimensional stable isotope approach. Journal of Environmental Quality 2018, 47:254-262.

26. Keppler F, Harper DB, Röckmann T, Moore RM, Hamilton JTG: New insight into the atmospheric chloromethane budget gained using stable carbon isotope ratios. Atmospheric Chemistry and Physics 2005, 5:2403-2411.

27. Doronina N, Sokolov A, Trotsenko YA: Isolation and initial characterization of aerobic chloromethane-utilizing bacteria. FEMS Microbiology Letters 1996, 142:179-183.

28. Hartmans S, Schmuckle A, Cook AM, Leisinger T: Methyl chloride: naturally occurring toxicant and C-1 growth substrate. Microbiology 1986, 132:1139-1142.

29. Traunecker J, Preuß A, Diekert G: Isolation and characterization of a methyl chloride utilizing, strictly anaerobic bacterium. Archives of Microbiology 1991, 156:416-421.

30. Freedman DL, Swamy M, Bell NC, Verce MF: Biodegradation of chloromethane by Pseudomonas aeruginosa strain NB1 under nitrate-reducing and aerobic conditions. Applied and Environmental Microbiology 2004, 70:4629-4634.

31. Schäfer H, McDonald IR, Nightingale PD, Murrell JC: Evidence for the presence of a CmuA methyltransferase pathway in novel marine methyl halide-oxidizing bacteria. Environmental Microbiology 2005, 7:839-852. 
32. Nadalig T, Greule M, Bringel F, Keppler F, Vuilleumier S: Probing the diversity of chloromethane-degrading bacteria by comparative genomics and isotopic fractionation. Frontiers in Microbiology 2014, 5:523.

33. Nadalig T, Ul Haque MF, Roselli S, Schaller H, Bringel F, Vuilleumier S: Detection and isolation of chloromethane-degrading bacteria from the Arabidopsis thaliana phyllosphere, and characterization of chloromethane utilization genes. FEMS Microbiology Ecology 2011, 77:438-448.

34. Doronina N, Ivanova E, Suzina N, Trotsenko YA: Methanotrophs and methylobacteria are found in woody plant tissues within the winter period. Microbiology 2004, 73:702-709.

35. Bringel F, Besaury L, Amato P, Kröber E, Kolb S, Keppler F, Vuilleumier S, Nadalig $\mathrm{T}$ : Methylotrophs and methylotroph populations for chloromethane degradation. Current Issues in Molecular Biology 2019, 33:149-172.

36. Vannelli T, Messmer M, Studer A, Vuilleumier S, Leisinger T: A corrinoiddependent catabolic pathway for growth of a Methylobacterium strain with chloromethane. PNAS USA 1999, 96:4615-4620.

37. Roselli S, Nadalig T, Vuilleumier S, Bringel F: The 380 kb pCMU01 plasmid encodes chloromethane utilization genes and redundant genes for vitamin $B$ 12and tetrahydrofolate-dependent chloromethane metabolism in Methylobacterium extorquens CM4: a proteomic and bioinformatics study. PLoS One 2013, 8:e56598.

38. Studer A, Vuilleumier S, Leisinger T: Properties of the methylcobalamin: H4folate methyltransferase involved in chloromethane utilization by Methylobacterium sp. strain CM4. European Journal of Biochemistry 1999, 264:242-249.

39. Studer A, Stupperich E, Vuilleumier S, Leisinger T: Chloromethane: tetrahydrofolate methyl transfer by two proteins from Methylobacterium chloromethanicum strain CM4. European Journal of Biochemistry 2001, 268:29312938.

40. Schäfer H, Miller LG, Oremland RS, Murrell JC: Bacterial cycling of methyl halides. Advances in Applied Microbiology 2007, 61:307-346.

41. Chaignaud P, Morawe M, Besaury L, Kröber E, Vuilleumier S, Bringel F, Kolb S: Methanol consumption drives the bacterial chloromethane sink in a forest soil. ISME Journal 2018, 12:2681-2693.

42. Cox MJ, Schäfer H, Nightingale PD, McDonald IR, Murrell JC: Diversity of methyl halide-degrading microorganisms in oceanic and coastal waters. FEMS Microbiology Letters 2012, 334:111-118.

43. Buddruhs N, Chertkov O, Petersen J, Fiebig A, Chen A, Pati A, Ivanova N, Lapidus A, Goodwin LA, Chain P: Complete genome sequence of the marine methyl-halide oxidizing Leisingera methylohalidivorans type strain (DSM 14336T), a representative of the Roseobacter clade. Standards in Genomic Sciences 2013, 9:128-141.

44. Chaignaud P, Maucourt B, Weiman M, Alberti A, Kolb S, Cruveiller S, Vuilleumier S, Bringel F: Genomic and transcriptomic analysis of growth-supporting dehalogenation of chlorinated methanes in Methylobacterium. Frontiers in Microbiology 2017, 8:1600.

45. Michener JK, Vuilleumier S, Bringel F, Marx CJ: Transfer of a catabolic pathway for chloromethane in Methylobacterium strains highlights different limitations for growth with chloromethane or with dichloromethane. Frontiers in Microbiology 2016, 7:1116. 
46. Piesik D, Weaver DK, Peck GE, Morrill WL: Diel patterns in volatiles released by mechanically-damaged wheat plants. Electronic Journal of Polish Agricultural Universities, Agronomy 2006, 9:1-12.

47. Piesik D, Łyszczarz A, Tabaka P, Lamparski R, Bocianowski J, Delaney K: Volatile induction of three cereals: influence of mechanical injury and insect herbivory on injured plants and neighbouring uninjured plants. Annals of Applied Biology 2010, 157:425-434.

48. Wang Z-P, Gulledge J, Zheng J-Q, Liu W, Li L-H, Han X-G: Physical injury stimulates aerobic methane emissions from terrestrial plants. Biogeosciences 2009, 6:615-621.

49. Chen Y, Murrell JC: When metagenomics meets stable-isotope probing: progress and perspectives. Trends in microbiology 2010, 18:157-163.

50. Kröber E, Eyice Ö: Profiling of active microorganisms by stable isotope probing metagenomics. In Stable Isotope Probing. Springer; 2019: 151-161

51. Coplen TB: Guidelines and recommended terms for expression of stable isotope ratio and gas ratio measurement results. Rapid Communications in Mass Spectrometry 2011, 25:2538-2560.

52. Atamna-Ismaeel N, Finkel OM, Glaser F, Sharon I, Schneider R, Post AF, Spudich JL, von Mering C, Vorholt JA, Iluz D, et al: Microbial rhodopsins on leaf surfaces of terrestrial plants. Environmental Microbiology 2011, 14:140-146.

53. Neufeld JD, Vohra J, Dumont MG, Lueders T, Manefield M, Friedrich MW, Murrell JC: DNA stable-isotope probing. Nature Protocols 2007, 2:860-866.

54. Liu W-T, Marsh TL, Cheng H, Forney LJ: Characterization of microbial diversity by determining terminal restriction fragment length polymorphisms of genes encoding 16S rRNA. Applied and Environmental Microbiology 1997, 63:4516-4522.

55. Ulrich A, Becker R: Soil parent material is a key determinant of the bacterial community structure in arable soils. FEMS Microbiology Ecology 2006, 56:430443.

56. Dunbar J, Ticknor LO, Kuske CR: Phylogenetic specificity and reproducibility and new method for analysis of terminal restriction fragment profiles of $16 \mathrm{~S}$ rRNA genes from bacterial communities. Applied and Environmental Microbiology 2001, 67:190-197.

57. Caporaso JG, Kuczynski J, Stombaugh J, Bittinger K, Bushman FD, Costello EK, Fierer N, Pena AG, Goodrich JK, Gordon JI, et al: QIIME allows analysis of highthroughput community sequencing data. Nature Methods 2010, 7:335-336.

58. Edgar RC: Search and clustering orders of magnitude faster than BLAST. Bioinformatics 2010, 26:2460-2461.

59. Edgar RC, Haas BJ, Clemente JC, Quince C, Knight R: UCHIME improves sensitivity and speed of chimera detection. Bioinformatics 2011, 27:2194-2200.

60. Li D, Liu C-M, Luo R, Sadakane K, Lam T-W: MEGAHIT: an ultra-fast singlenode solution for large and complex metagenomics assembly via succinct de Bruijn graph. Bioinformatics 2015, 31:1674-1676.

61. Alneberg J, Bjarnason BS, de Bruijn I, Schirmer M, Quick J, Ijaz UZ, Lahti L, Loman $\mathrm{NJ}$, Andersson AF, Quince $\mathrm{C}$ : Binning metagenomic contigs by coverage and composition. Nature Methods 2014, 11:1144-1146.

62. Kang D, Li F, Kirton ES, Thomas A, Egan RS, An H, Wang Z: MetaBAT 2: an adaptive binning algorithm for robust and efficient genome reconstruction from metagenome assemblies. Journal of Life \& Environmental Sciences (PeerJ) Preprints 2019, 7:e27522v27521. 
63. $\mathrm{Wu} \mathrm{Y}-\mathrm{W}$, Simmons BA, Singer SW: MaxBin 2.0: an automated binning algorithm to recover genomes from multiple metagenomic datasets. Bioinformatics 2015 , 32:605-607.

64. Langmead B, Salzberg SL: Fast gapped-read alignment with Bowtie 2. Nature Methods 2012, 9:357-359.

65. Uritskiy GV, DiRuggiero J, Taylor J: MetaWRAP — a flexible pipeline for genomeresolved metagenomic data analysis. Microbiome 2018, 6:158.

66. Parks DH, Imelfort M, Skennerton CT, Hugenholtz P, Tyson GW: CheckM: assessing the quality of microbial genomes recovered from isolates, single cells, and metagenomes. Genome Research 2015, 25:1043-1055.

67. Brettin T, Davis JJ, Disz T, Edwards RA, Gerdes S, Olsen GJ, Olson R, Overbeek R, Parrello B, Pusch GD, et al: RASTtk: a modular and extensible implementation of the RAST algorithm for building custom annotation pipelines and annotating batches of genomes. Scientific Reports 2015, 5:8365-8365.

68. Zuo G, Hao B: CVTree3 Web Server for whole-genome-based and alignment-free prokaryotic phylogeny and taxonomy. Genomics Proteomics Bioinformatics 2015, 13:321-331.

69. Letunic I, Bork P: Interactive Tree Of Life (iTOL) v4: recent updates and new developments. Nucleic Acids Research 2019, 47:W256-W259.

70. Asnicar F, Thomas AM, Beghini F, Mengoni C, Manara S, Manghi P, Zhu Q, Bolzan M, Cumbo F, May U, et al: Precise phylogenetic analysis of microbial isolates and genomes from metagenomes using PhyloPhlAn 3.0. Nature Communications 2020, 11:2500.

71. Kumar S, Stecher G, Li M, Knyaz C, Tamura K: MEGA X: Molecular evolutionary genetics analysis across computing platforms. Molecular Biology and Evolution 2018, 35:1547-1549.

72. Jain C, Rodriguez-R LM, Phillippy AM, Konstantinidis KT, Aluru S: High throughput ANI analysis of $90 \mathrm{~K}$ prokaryotic genomes reveals clear species boundaries. Nature Communications 2018, 9:5114.

73. Altschul SF, Gish W, Miller W, Myers EW, Lipman DJ: Basic local alignment search tool. Journal of Molecular Biology 1990, 215:403-410.

74. Seemann T: Prokka: rapid prokaryotic genome annotation. Bioinformatics 2014, 30:2068-2069.

75. Kaminski J, Gibson MK, Franzosa EA, Segata N, Dantas G, Huttenhower C: Highspecificity targeted functional profiling in microbial communities with ShortBRED. PLoS computational biology 2015, 11:e1004557.

76. Vallenet D, Calteau A, Dubois M, Amours P, Bazin A, Beuvin M, Burlot L, Bussell X, Fouteau S, Gautreau G, et al: MicroScope: an integrated platform for the annotation and exploration of microbial gene functions through genomic, pangenomic and metabolic comparative analysis. Nucleic Acids Research 2019, 48:D579-D589.

77. Vallenet D, Calteau A, Dubois M, Amours P, Bazin A, Beuvin M, Burlot L, Bussell X, Fouteau S, Gautreau G, et al: MicroScope: an integrated platform for the annotation and exploration of microbial gene functions through genomic, pangenomic and metabolic comparative analysis. Nucleic Acids Research 2020, 48:D579-D589.

78. Aziz RK, Bartels D, Best AA, DeJongh M, Disz T, Edwards RA, Formsma K, Gerdes S, Glass EM, Kubal M: The RAST Server: rapid annotations using subsystems technology. BMC Genomics 2008, 9:1-15. 
79. Aslan-Üzel AS, Beier A, Kovář D, Cziegler C, Padhi SK, Schuiten ED, Dörr M, Böttcher D, Hollmann F, Rudroff F: An ultrasensitive fluorescence assay for the detection of halides and enzymatic dehalogenation. The European Society Journal for Catalysis 2020, 12:2032-2039.

80. Blom J, Albaum SP, Doppmeier D, Pühler A, Vorhölter F-J, Zakrzewski M, Goesmann A: EDGAR: a software framework for the comparative analysis of prokaryotic genomes. BMC Bioinformatics 2009, 10:154.

81. Kröber E, Schäfer H: Identification of proteins and genes expressed by Methylophaga thiooxydans during growth on dimethylsulfide and their presence in other members of the genus. Frontiers in Microbiology 2019, 10:1132.

82. Madhaiyan M, Poonguzhali S, Senthilkumar M, Lee J-S, Lee K-C: Methylobacterium gossipiicola sp. nov., a pink-pigmented, facultatively methylotrophic bacterium isolated from the cotton phyllosphere. International Journal of Systematic and Evolutionary Microbiology 2012, 62:162-167.

83. Bringel F, Couée I: Pivotal roles of phyllosphere microorganisms at the interface between plant functioning and atmospheric trace gas dynamics. Frontiers in Microbiology 2015, 6:486.

84. Knief C, Frances L, Vorholt JA: Competitiveness of diverse Methylobacterium strains in the phyllosphere of Arabidopsis thaliana and identification of representative models, including M. extorquens PA1. Microbial Ecology 2010, 60:440-452.

85. Knief C, Ramette A, Frances L, Alonso-Blanco C, Vorholt JA: Site and plant species are important determinants of the Methylobacterium community composition in the plant phyllosphere. The ISME Journal 2010, 4:719-728.

86. Delmotte N, Knief C, Chaffron S, Innerebner G, Roschitzki B, Schlapbach R, von Mering $\mathrm{C}$, Vorholt JA: Community proteogenomics reveals insights into the physiology of phyllosphere bacteria. PNAS USA 2009, 106:16428-16433.

87. Raja P, Balachandar D, Sundaram S: Genetic diversity and phylogeny of pinkpigmented facultative methylotrophic bacteria isolated from the phyllosphere of tropical crop plants. Biology and Fertility of Soils 2008, 45:45-53.

88. Minami T, Anda M, Mitsui H, Sugawara M, Kaneko T, Sato S, Ikeda S, Okubo T, Tsurumaru $\mathrm{H}$, Minamisawa $\mathrm{K}$ : Metagenomic analysis revealed methylamine and ureide utilization of soybean-associated Methylobacterium. Microbes and Environments 2016:ME16035.

89. Madhaiyan M, Poonguzhali S, Kwon S-W, Sa T-M: Methylobacterium phyllosphaerae sp. nov., a pink-pigmented, facultative methylotroph from the phyllosphere of rice. International Journal of Systematic and Evolutionary Microbiology 2009, 59:22-27.

90. Vorholt JA: Microbial life in the phyllosphere. Nature Reviews Microbiology 2012, 10:828-840.

91. Karasov TL, Neumann M, Duque-Jaramillo A, Kersten S, Bezrukov I, Schröppel B, Symeonidi E, Lundberg DS, Regalado J, Shirsekar G: The relationship between microbial population size and disease in the Arabidopsis thaliana phyllosphere. BioRxiv 2020:828814.

92. Perazzolli M, Nesler A, Giovannini O, Antonielli L, Puopolo G, Pertot I: Ecological impact of a rare sugar on grapevine phyllosphere microbial communities. Microbiological Research 2020, 232:126387.

93. Chen Q-L, An X-L, Zheng B-X, Ma Y-B, Su J-Q: Long-term organic fertilization increased antibiotic resistome in phyllosphere of maize. Science of the Total Environment 2018, 645:1230-1237. 
94. Zwielehner J, Handschur M, Michaelsen A, Irez S, Demel M, Denner EB, Haslberger AG: DGGE and real time PCR analysis of lactic acid bacteria in bacterial communities of the phyllosphere of lettuce. Molecular Nutrition \& Food Research 2008, 52:614-623.

95. Jackson CR, Denney WC: Annual and seasonal variation in the phyllosphere bacterial community associated with leaves of the southern magnolia (Magnolia grandiflora). Microbial Ecology 2011, 61:113-122.

96. Rogers TJ, Leppanen C, Brown V, Fordyce JA, LeBude A, Ranney T, Simberloff D, Cregger MA: Exploring variation in phyllosphere microbial communities across four hemlock species. Ecosphere 2018, 9:e02524.

97. Aydogan EL, Budich O, Hardt M, Choi YH, Jansen-Willems AB, Moser G, Müller C, Kämpfer P, Glaeser SP: Global warming shifts the composition of the abundant bacterial phyllosphere microbiota as indicated by a cultivation dependent and independent study of the grassland phyllosphere of a long-term warming fieldexperiment. FEMS Microbiology Ecology 2020, 96.

98. Santana RS, Fernandes G, Ávila MP, Reis MP, de Araújo FM, Salim A, Oliveira G, Chartone-Souza E, Nascimento A: Endophytic microbiota associated with the root tips and leaves of Baccharis dracunculifolia. Brazilian Archives of Biology and Technology 2016, 59.

99. Herrmann M, Geesink P, Richter R, Küsel K: Canopy position has a stronger effect than tree species identity on phyllosphere bacterial diversity in a floodplain hardwood forest. Plant Microbe Interactions 2020, 81:157-168.

100. Albuquerque L, da Costa M: The Families Conexibacteraceae, Patulibacteraceae and Solirubrobacteraceae. The Prokaryotes Springer Berlin Heidelberg 2014:185200.

101. Fausto C, Mininni AN, Sofo A, Crecchio C, Scagliola M, Dichio B, Xiloyannis C: Olive orchard microbiome: characterisation of bacterial communities in soilplant compartments and their comparison between sustainable and conventional soil management systems. Plant Ecology \& Diversity 2018, 11:597-610.

102. Ottesen A, Ramachandran P, Reed E, Gu G, Gorham S, Ducharme D, Newell M, Rideout S, Turini T, Hill T: Metagenome tracking biogeographic agroecology: phytobiota of tomatoes from Virginia, Maryland, North Carolina and California. Food Microbiology 2019, 79:132-136.

103. Moore-Colyer MJ, Longland A, Harris P, Crosthwaite S: Mapping the bacterial ecology on the phyllosphere of grass hay and the potential hazards of soaking fodder for horse gut health. BioRxiv 2018:494799.

104. Beck DA, McTaggart TL, Setboonsarng U, Vorobev A, Goodwin L, Shapiro N, Woyke T, Kalyuzhnaya MG, Lidstrom ME, Chistoserdova L: Multiphyletic origins of methylotrophy in Alphaproteobacteria, exemplified by comparative genomics of Lake Washington isolates. Environmental microbiology 2015, 17:547-554.

105. Wiegel J, Wilke D, Baumgarten J, Opitz R, Schlegel HG: Transfer of the nitrogenfixing hydrogen bacterium Corynebacterium autotrophicum Baumgarten et al. to Xanthobacter gen. nov. International Journal of Systematic and Evolutionary Microbiology 1978, 28:573-581.

106. Yashiro E, Spear R, McManus P: Culture dependent and culture-independent assessment of bacteria in the apple phyllosphere. Journal of Applied Microbiology 2011, 110:1284-1296.

107. Darlison J, Mogren L, Rosberg AK, Grudén M, Minet A, Liné C, Mieli M, Bengtsson $\mathrm{T}$, Håkansson $\AA$, Uhlig E: Leaf mineral content govern microbial community 
structure in the phyllosphere of spinach (Spinacia oleracea) and rocket (Diplotaxis tenuifolia). Science of The Total Environment 2019, 675:501-512.

108. Laforest-Lapointe I, Messier C, Kembel SW: Tree phyllosphere bacterial communities: exploring the magnitude of intra-and inter-individual variation among host species. Journal of Life \& Environmental Sciences (PeerJ 2016, 4:e2367.

109. Chaignaud P, Morawe M, Besaury L, Kröber E, Vuilleumier S, Bringel F, Kolb S: Methanol consumption drives the bacterial chloromethane sink in a forest soil. The ISME journal 2018, 12:2681-2693.

110. Studer A, McAnulla C, Büchele R, Leisinger T, Vuilleumier S: Chloromethaneinduced genes define a third $\mathrm{C} 1$ utilization pathway in Methylobacterium chloromethanicum CM4. Journal of Bacteriology 2002, 184:3476-3484.

111. Vuilleumier S, Chistoserdova L, Lee M-C, Bringel F, Lajus A, Zhou Y, Gourion B, Barbe V, Chang J, Cruveiller S: Methylobacterium genome sequences: a reference blueprint to investigate microbial metabolism of $\mathrm{C} 1$ compounds from natural and industrial sources. PLoS One 2009, 4:e5584.

112. Marx CJ, Bringel F, Chistoserdova L, Moulin L, U1 Haque MF, Fleischman DE, Gruffaz C, Jourand P, Knief C, Lee M-C: Complete genome sequences of six strains of the genus Methylobacterium. Journal of Bacteriology 2012, 194:4746-4748.

113. Kwak M-J, Jeong H, Madhaiyan M, Lee Y, Sa T-M, Oh TK, Kim JF: Genome information of Methylobacterium oryzae, a plant-probiotic methylotroph in the phyllosphere. PLoS One 2014, 9:e106704.

114. Lex A, Gehlenborg N, Strobelt H, Vuillemot R, Pfister H: UpSet: visualization of intersecting sets. IEEE Transactions on Visualization and Computer Graphics 2014, 20:1983-1992.

115. Bahlmann E, Keppler F, Wittmer J, Greule M, Schöler HF, Seifert R, Zetzsch C: Evidence for a major missing source in the global chloromethane budget from stable carbon isotopes. Atmospheric Chemistry and Physics 2019, 19:1703-1719.

116. Keppler F, Bahlmann E, Greule M, Schöler HF, Wittmer J, Zetzsch C: Mass spectrometric measurement of hydrogen isotope fractionation for the reactions of chloromethane with $\mathbf{O H}$ and Cl. Atmospheric Chemistry and Physics 2018, 18:6625-6635.

117. Keppler F, Barnes JD, Horst A, Bahlmann E, Luo J, Nadalig T, Greule M, Hartmann $\mathrm{SC}$, Vuilleumier S: Chlorine isotope fractionation of the major chloromethane degradation processes in the environment. Environmental Science \& Technology 2019, 54:1634-1645.

118. Tani A, Ogura Y, Hayashi T, Kimbara K: Complete genome sequence of Methylobacterium aquaticum strain $22 \mathrm{~A}$, isolated from Racomitrium japonicum moss. Genome Announcements 2015, 3.

119. Madhaiyan M, Poonguzhali S: Methylobacterium pseudosasicola sp. nov. and Methylobacterium phyllostachyos sp. nov., isolated from bamboo leaf surfaces. International Journal of Systematic and Evolutionary Microbiology 2014, 64:23762384.

120. Kang Y-S, Kim J, Shin H-D, Nam Y-D, Bae J-W, Jeon CO, Park W: Methylobacterium platani sp. nov., isolated from a leaf of the tree Platanus orientalis. International Journal of Systematic and Evolutionary Microbiology 2007, 57:2849-2853.

121. Chaudhry V, Baindara P, Pal VK, Chawla N, Patil PB, Korpole S: Methylobacterium indicum sp. nov., a facultative methylotrophic bacterium isolated from rice seed. Systematic and Applied Microbiology 2016, 39:25-32. 
122. Ardley J, Tian R, Howieson J, Yates R, Bräu L, Han J, Lobos E, Huntemann M, Chen A, Mavromatis K: Genome sequence of the dark pink pigmented Listia bainesii microsymbiont Methylobacterium sp. WSM2598. Standards in Genomic Sciences 2014, 9:1-9.

123. Gallego V, García MT, Ventosa A: Methylobacterium variabile sp. nov., a methylotrophic bacterium isolated from an aquatic environment. International Journal of Systematic and Evolutionary Microbiology 2005, 55:1429-1433.

124. Belkhelfa S, Labadie K, Cruaud C, Aury J-M, Roche D, Bouzon M, Salanoubat M, Döring V: Complete genome sequence of the facultative methylotroph Methylobacterium extorquens TK 0001 isolated from soil in Poland. Genome Announcements 2018, 6.

958

959

960

961

962

125. Van Aken B, Tehrani R, Schnoor JL: Endophyte-assisted phytoremediation of explosives in poplar trees by Methylobacterium populi BJ001(T). In Endophytes of Forest Trees. Springer; 2011:217-234

126. Wang X, Sahr F, Xue T, Sun B: Methylobacterium salsuginis sp. nov., isolated from seawater. International Journal of Systematic and Evolutionary Microbiology 2007, 57:1699-1703. 


\section{Figure 1. Relative abundance of ${ }^{13} \mathrm{C}$-labelled bacterial OTUs on genus level from}

967 fraction samples LEAF, LEAFWASH and SOIL. OTUs are classified as 'labelled' by the following criteria: 1) ${ }^{13} \mathrm{C}$-heavy $>{ }^{12} \mathrm{C}$-heavy; 2) ${ }^{13} \mathrm{C}$-heavy $>{ }^{13} \mathrm{C}$-light; 3) ${ }^{13} \mathrm{C}$-[heavy-light] $>$ ${ }^{12} \mathrm{C}$-[heavy-light]; 4) ${ }^{13} \mathrm{C}[$ Heavy-Light $]>$ threshold, with threshold $=0.005 \%$. The taxonomic affiliation of each labeled OTU is indicated at the family, order and genus levels (4-6, respectively), with a specific color and capital letter (see legend box).

972

Figure 2. Maximum-likelihood phylogenetic trees showing the position of selected MAGs within a tree of closely related reference genomes. Multiple sequence alignments of concatenated marker genes were constructed using PhyloPhIAn 3.0. Phylogenetic analysis was performed based on a matrix of pairwise distances estimated using the $L G+F+G+I$ model with 500 bootstrap replications. Numbers at branch nodes refer to bootstrap values. (A) Phylogenetic tree of Methylobacterium species. Two metagenomic bins isolated from the LEAF fraction were classified as Methylobacterium (marked in pink and purple) and were placed within 19 selected reference genomes of Alphaproteobacteria. Tree was annotated with ANI and AAl values in relation to 'Fern $\mathrm{CH}_{3} \mathrm{Cl}$ SIP LEAF bin s3'. (B) Phylogenetic tree of Propionibacterium species. Two bins classified as related to Propionobacterium (marked in yellow) from fractions LEAF and LEAFWASH were placed in a tree with 7 selected reference genomes from Microlunatus and Friedmaniella. Annotated ANI and AAI values are in relation to 'Fern $\mathrm{CH}_{3} \mathrm{Cl}$ SIP LEAF bin co3'. (C) Phylogenetic tree of Myxococcales species. Two bins classified as related to Sorangium (marked in green) from fraction SOIL were placed in a tree with 16 reference genomes of Deltaproteobacteria. Tree was annotated with ANI and AAI values in relation to 'Fern $\mathrm{CH}_{3} \mathrm{Cl}$ SIP SOIL bin s1'; AAI values significantly under 50 and ANI values significantly under 70 were not computed and are annotated with NA. 
Figure 3. Metabolic reconstruction of $\left[{ }^{13} \mathrm{C}\right]-\mathrm{CH}_{3} \mathrm{Cl}$ labelled metagenome assembled genomes. A coloured dot next to a gene or pathway shows presence of this pathway or gene

993 in the corresponding genome. 'Fern $\mathrm{CH}_{3} \mathrm{Cl}$ SIP LEAF bin s3' is represented by a pink dot, 994 'Fern $\mathrm{CH}_{3} \mathrm{Cl}$ SIP LEAF bin co1' is highlighted in purple, 'Fern $\mathrm{CH}_{3} \mathrm{Cl}$ SIP LEAF bin co3' is represented with a yellow dot and 'Fern $\mathrm{CH}_{3} \mathrm{CI}$ SIP SOIL bin $\mathrm{s} 1$ ' is highlighted in green.

Figure 4. Pan-genome analysis of genomes from 10 Methylobacterium isolated strains,

3 representatives of the closely related clade Methylorubrum and two $\left[{ }^{13} \mathrm{C}\right]-\mathrm{CH}_{3} \mathrm{Cl}-$ enriched fern leaf MAGs. (A) Fractional pan genome representation. (B) UpSet plot of the pan-genome of the 15 Methylobacterium genomes. The metagenomic bin ' $\mathrm{Fern} \mathrm{CH}_{3} \mathrm{Cl}$ SIP LEAF bin s3' was chosen as reference genome. The analysis was carried out using the "Efficient Database framework for comparative Genome Analyses using BLAST score Ratios" (EDGAR) platform.

1004

Supplementary Figure S1. Plant growth chambers setup. A) Details of gas-tight plant chamber. Gas-tight plant chambers were constructed with acryl glass (thickness: $5 \mathrm{~mm}$ ). Butyl rubber stoppers at the top and the lower part of the chamber were used as ports for injecting $\mathrm{CH}_{3} \mathrm{Cl}$ and extracting gas samples. A small ventilator in the lower part of the chamber ensured an even distribution of the gases in the chamber

B) Gas-tight plant chambers with fern plants inside at the end of the incubation period. Aluminium foil was wrapped around the chambers during incubation with $\mathrm{CH}_{3} \mathrm{Cl}$ to reduce photosynthesis and microbial $\mathrm{CO}_{2}$ consumption during the labelling experiment. Sunlight entered the chambers through the clear top of the chamber.

1015 Supplementary Figure S2. Monitoring of the SIP-incubation of ferns. Incubations were

1016 carried out over 19 days with three biological replicated intact fern plants in gas-tight

1017 incubation chambers per tested condition. At the start of the SIP-incubation, $20 \mathrm{~mL} \mathrm{CH} \mathrm{Cl}_{3}$

1018 was added to the chambers (initial mixing ratio of $\sim 200 \mathrm{ppm}$ ) and degradation was 
1019 monitored with GC-MS. At the end of each day, incubation chambers were opened and

1020 ventilated overnight. From day 2 of the incubation, $10 \mathrm{~mL} \mathrm{CH}{ }_{3} \mathrm{Cl}$ was added to the chambers

1021 (initial mixing ratio of $\sim 100 p p m$ ). (A) ${ }^{13} \mathrm{C}$-labelled $\mathrm{CH}_{3} \mathrm{Cl}$, and $(\mathrm{B}){ }^{12} \mathrm{C}$-labelled $\mathrm{CH}_{3} \mathrm{Cl}$. Red

1022 arrows indicate point of $\mathrm{CH}_{3} \mathrm{Cl}$ addition.

1023

1024 Supplementary Figure S3. Analysis of carbon mass fraction (C \%) and differential

1025 stable carbon isotope ratio $\left(\delta^{13} \mathrm{C}\right.$ value) of fern leaves and washed leaf samples $\left(\mathrm{T}_{\text {end }}\right.$

1026 washed) via EA/IRMS. Stable isotope ratios $\left(\delta^{13} \mathrm{C}\right)$ are expressed in permil (\%) relative to

1027 the international standard.

1028

1029

1030

1031

1032

1033

1034

1035

1036

1037

1038 
Figure 1. Relative abundance of ${ }^{13} \mathrm{C}$-labelled bacterial OTUs on genus level from fraction samples LEAF, LEAFWASH and SOIL. OTUs are classified as 'labelled' by the following criteria: 1) ${ }^{13} \mathrm{C}$-heavy $>{ }^{12} \mathrm{C}$-heavy; 2) ${ }^{13} \mathrm{C}$-heavy $>{ }^{13} \mathrm{C}$-light; 3) ${ }^{13} \mathrm{C}$-[heavy-light] $>{ }^{12} \mathrm{C}$ [heavy-light]; 4) ${ }^{13} \mathrm{C}$ [Heavy-Light] > threshold, with threshold $=0.005 \%$. The taxonomic affiliation of each labeled OTU is indicated at the family, order and genus levels (4-6, respectively), with a specific color and capital letter (see legend box).

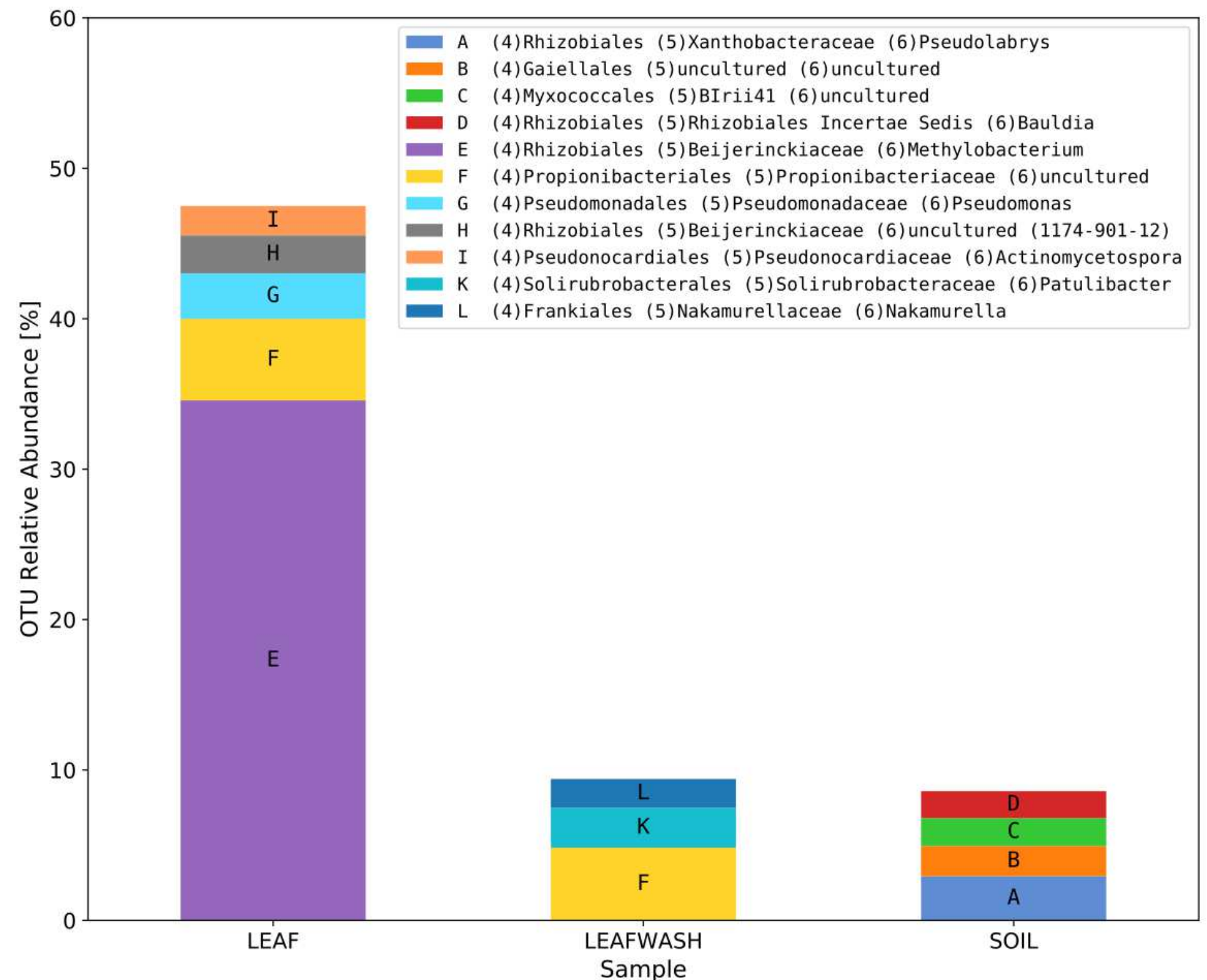


Figure 2. Maximum-likelihood phylogenetic trees showing the position of selected MAGs within tree of closely related reference genomes. Multiple sequence alignments of

concatenated marker genes were constructed using PhyloPhIAn 3.0. Phylogenetic analysis was performed based on a matrix of pairwise distances estimated using the $L G+F+G+I$ model with 500 bootstrap replications. Numbers at branch nodes refer to bootstrap values. (A) Phylogenetic tree of Methylobacterium species. Two metagenomic bins isolated from the LEAF fraction were classified as Methylobacterium (marked in pink and purple) and were placed within 19 selected reference genomes of Alphaproteobacteria. Tree was annotated with ANI and AAI values in relation to 'Fern $\mathrm{CH}_{3} \mathrm{Cl}$ SIP LEAF bin s3'. (B) Phylogenetic tree of Propionibacterium species. Two bins classified as related to Propionobacterium (marked in yellow) from fractions LEAF and LEAFWASH were placed in a tree with 7 selected reference genomes from Microlunatus and Friedmaniella. Annotated ANI and AAI values are in relation to 'Fern CH ${ }_{3} \mathrm{Cl}$ SIP LEAF bin co3'. (C) Phylogenetic tree of Myxococcales species. Two bins classified as related to Sorangium (marked in green) from fraction SOIL were placed in a tree with 16 reference genomes of of Deltaproteobacteria. Tree was annotated with ANI and AAI values in relation to 'Fern $\mathrm{CH}_{3} \mathrm{Cl}$ SIP SOIL bin s1'; AAl values significantly under 50 and ANI values significantly under 70 were not computed and are annotated with NA.

A

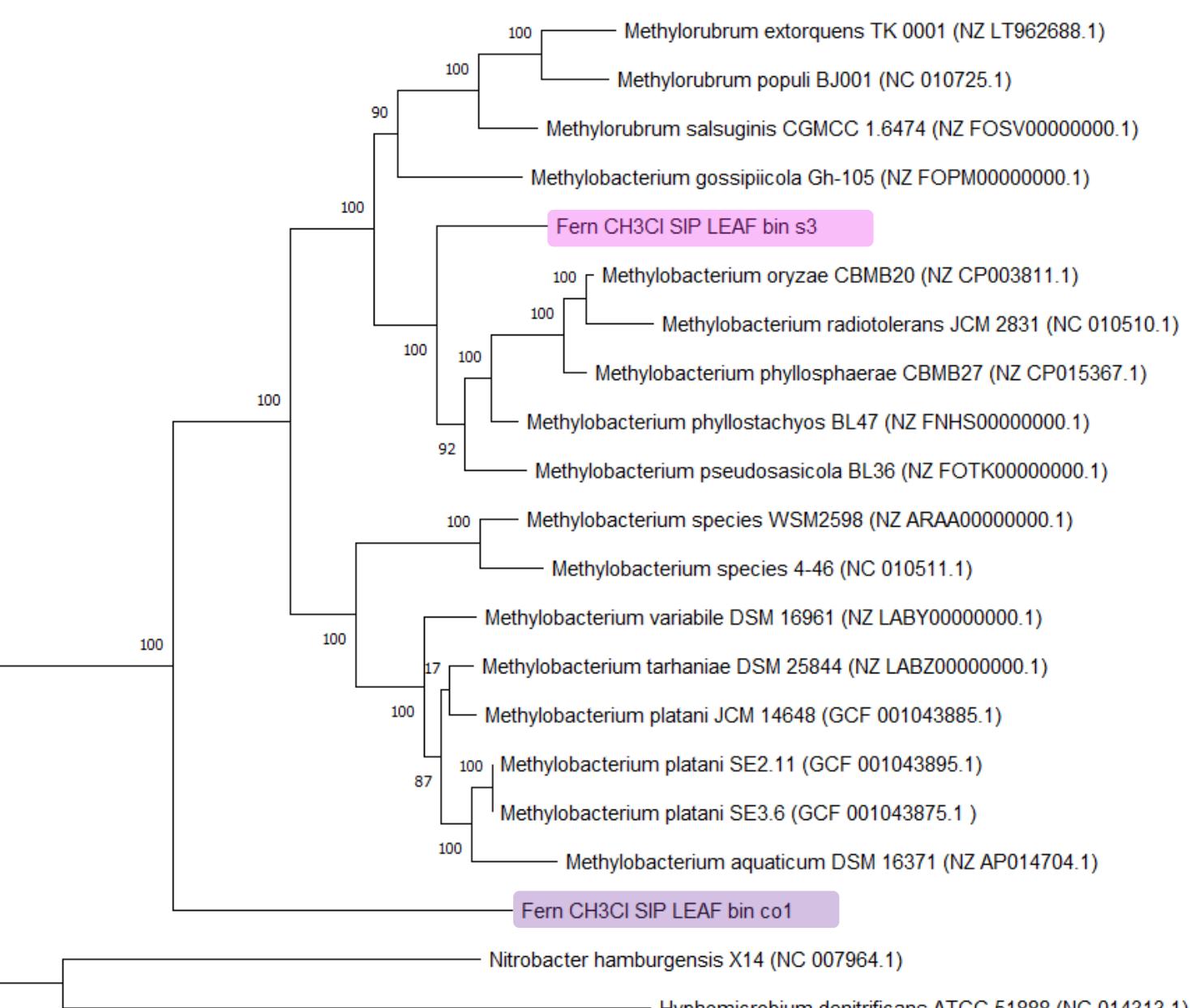

\section{ANI}

80.50

80.62

80.69

80.08

82.50

82.90

82.58

82.29

82.14

79.29

79.51

79.75

79.77

79.95

79.76

79.79

79.70

77.46

\section{AAI}

71.31

71.07

71.29

71.82

78.49

78.56

78.42

78.04

78.14

68.54

68.82

68.32

68.1

68.48

68.51

68.43

68.5

62.41

56.96

54.26 

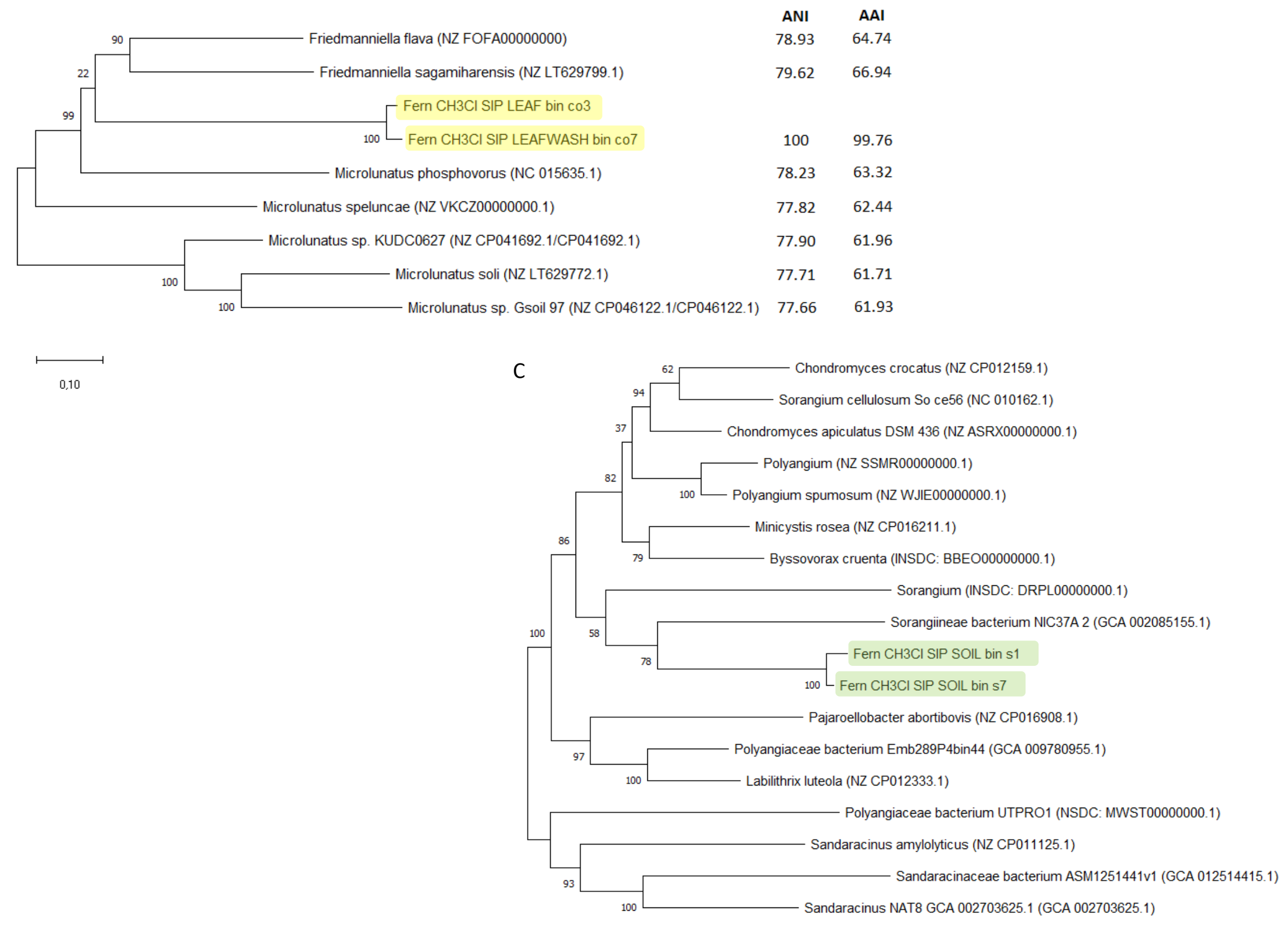


\section{Central carbon metabolism}

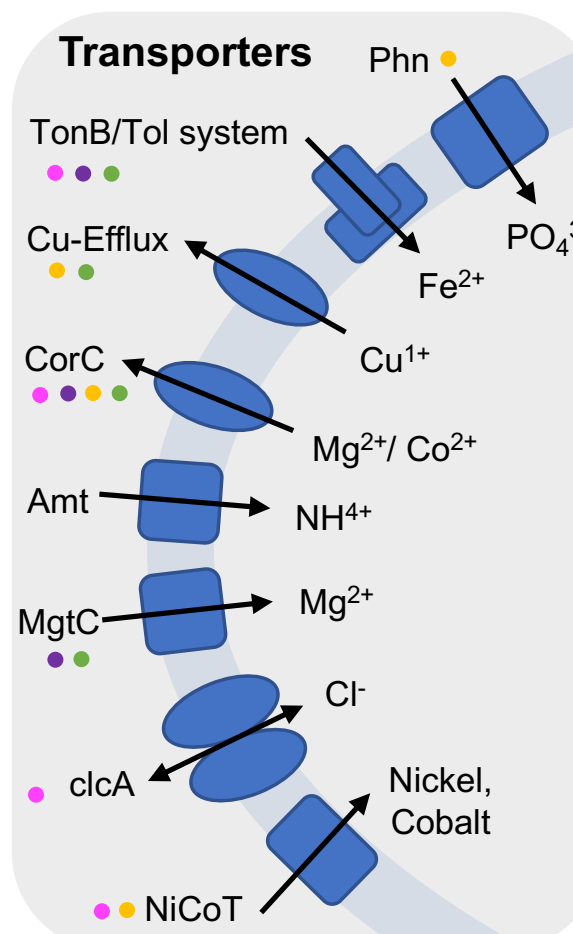

\section{Stress response}

- osmotic stress response (osmoregulated periplasmic glucans/glycine betaine)

- $\quad$ superoxide dismutase (Fe, Cu$\mathrm{Zn)}$

- peroxidase, catalase

- glutathione $\bullet \bullet$

- periplasmatic stress response
Glycolysis glucose<smiles>CCCCCCC</smiles>

Gluconeogenesis

se-Phosphate $\bullet$

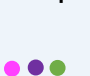

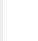
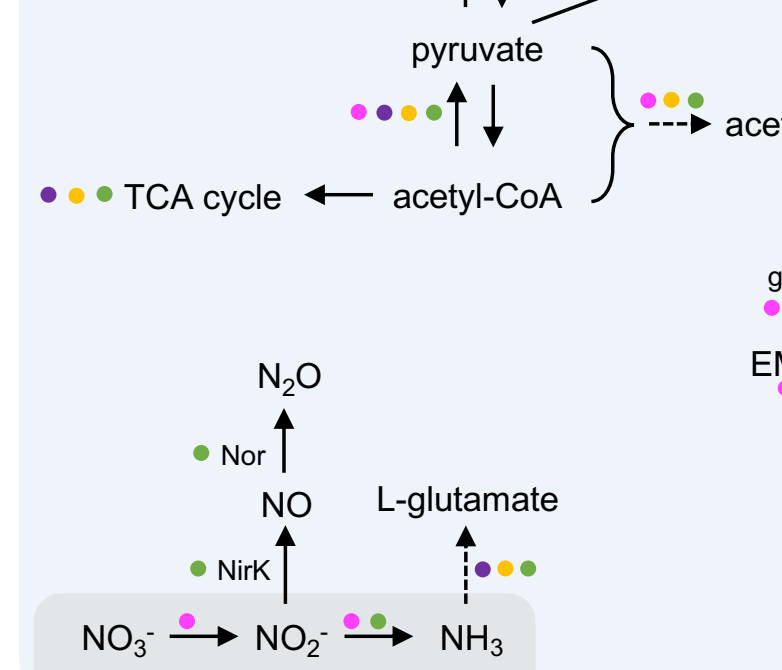

Nitrate and nitrite

ammonification $\mathrm{CHO}-\mathrm{H}_{4} \mathrm{~F}$

\section{Electron transfer}

\section{Fumarate}

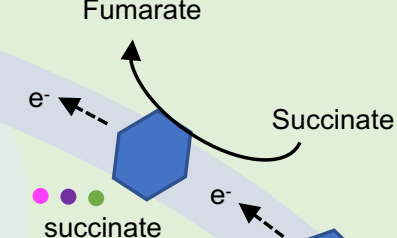

succinate

dehydrogenase

quinone oxidoreductase
बुिA cetate Gly

Gly $\mathrm{CH}_{3}-\mathrm{H}_{4} \mathrm{~F}$ glyA $\downarrow$ GCP $\downarrow$ तett $\mathrm{EMCP} \longleftarrow \mathrm{CH}_{2} \equiv \mathrm{H}_{4} \mathrm{~F}$ • FolD $\downarrow$ A MtdA $\mathrm{CH}=\mathrm{H}_{4} \mathrm{~F}$

- FolD $\downarrow \begin{gathered}i \wedge \\ \forall i\end{gathered}$

— F FftL $\downarrow \downarrow$ i Puru • formate formaldehyde

$\begin{array}{lll}\mathrm{CH}_{2}=\mathrm{H}_{4} \mathrm{MPT} & \begin{array}{l}\mathrm{Fae} \\ \text { spont. }\end{array}\end{array}$

$\downarrow \mathrm{MtdB}$ 。

$\mathrm{CH}-\mathrm{H}_{4} \mathrm{MPT}$

$\downarrow$ Mch $\bullet$

$\mathrm{N}^{5}-\mathrm{CHO}-$

$\mathrm{H}_{4} \mathrm{MPT}$

$\downarrow \mathrm{Ftr}$

CHO-MFR

FmdABC

Fhc
C-type

cytochrome

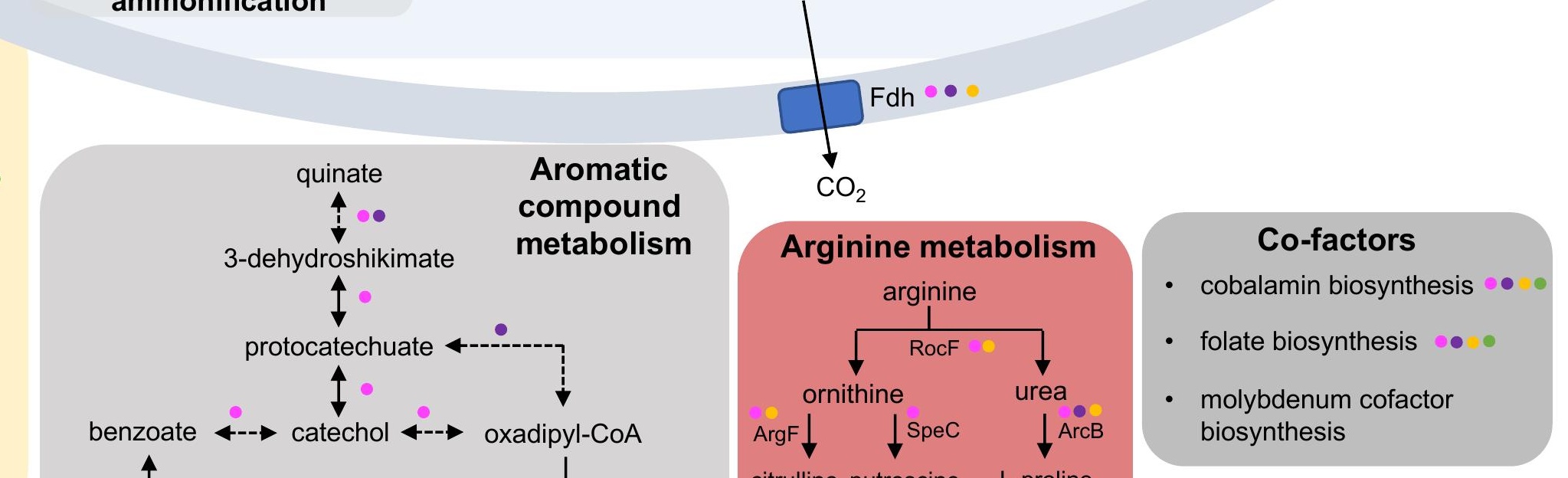

citrulline putrescine L-proline OppABCDF 
Figure 4. Pan-genome analysis of 13 Methylobacterium genomes of isolated strains and two [ $\left.{ }^{13} \mathrm{C}\right]-\mathrm{CH}_{3} \mathrm{Cl}$-enriched fern leaf $\mathrm{MAGs}$. (A) Fractional pan genome representation. (B) UpSet plot of the pan-genome of the 15 Methylobacterium genomes. The metagenomic bin ' $\mathrm{Fern} \mathrm{CH}_{3} \mathrm{Cl}$ SIP LEAF bin s3' was chosen as reference genome. The analysis was carried out using the "Efficient Database framework for comparative Genome Analyses using BLAST score Ratios" (EDGAR) platform.

A

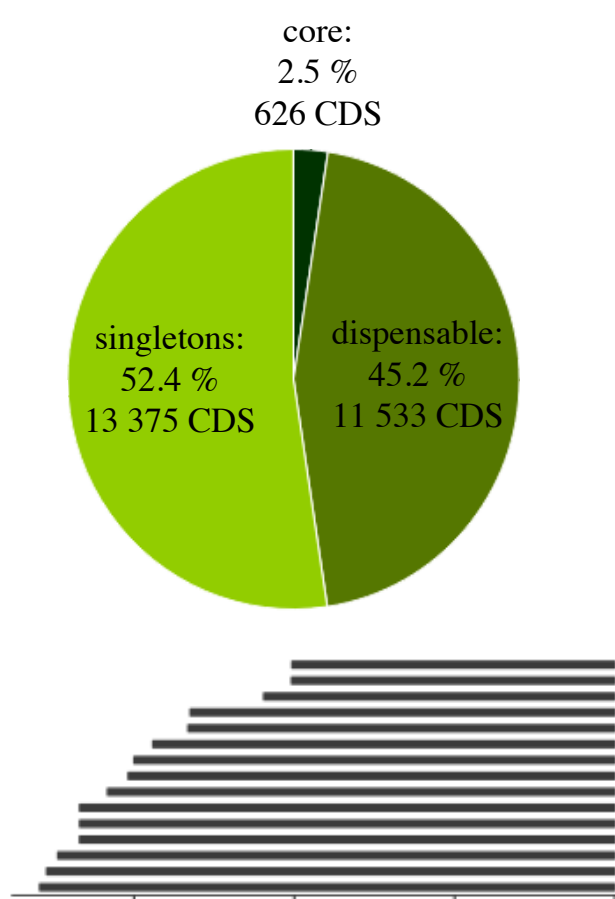

4000
CDS per organism / Contig
B

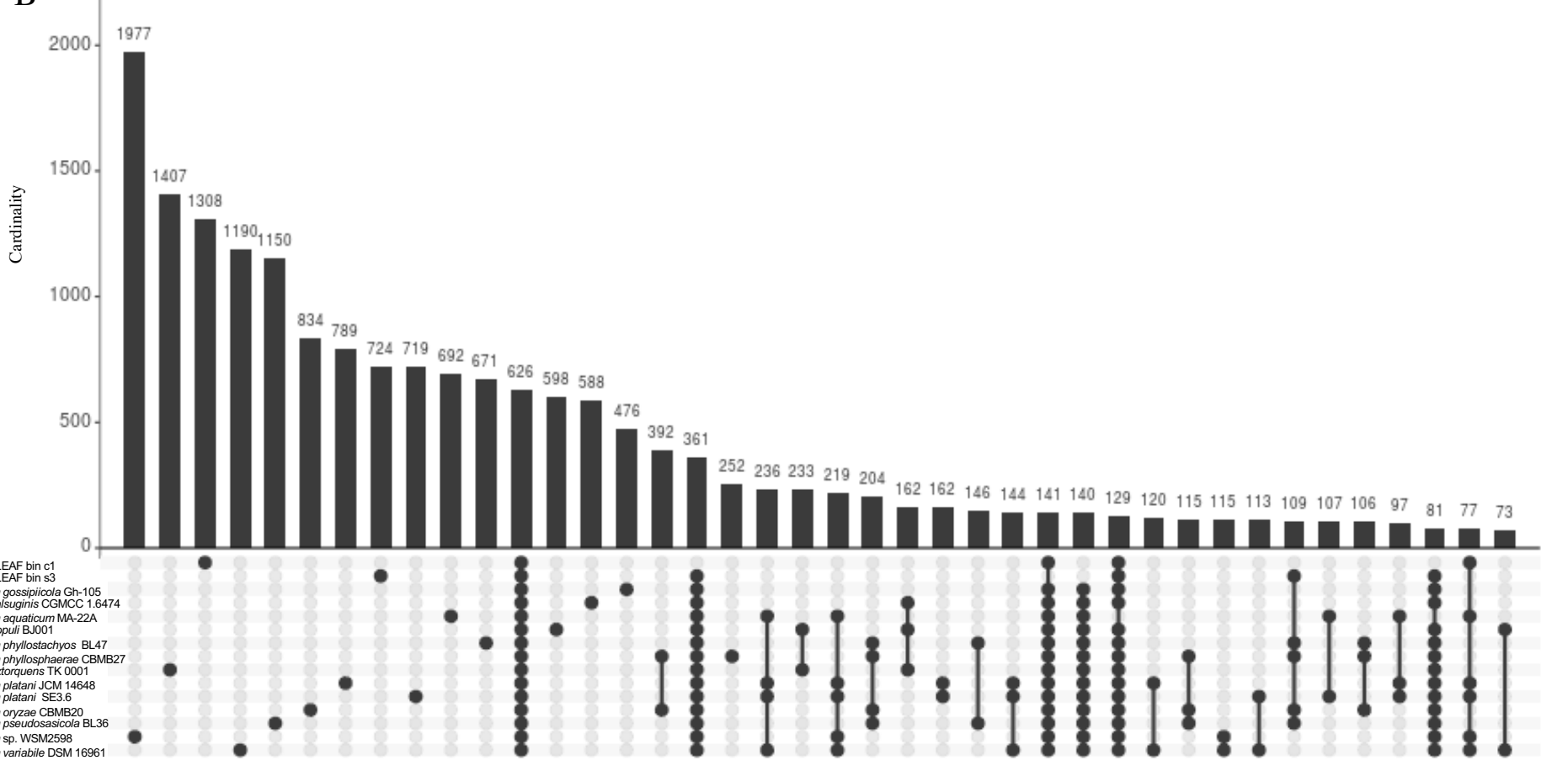


Supplementary Figure S1. Plant growth chamber setup. A) Details of gas-tight plant chamber. Gas-tight plant chambers were constructed with acryl glass (thickness: $5 \mathrm{~mm}$ ). Butyl rubber stoppers at the top and the lower part of the chamber were used as ports for injecting $\mathrm{CH}_{3} \mathrm{Cl}$ and extracting gas samples. A small ventilator in the lower part of the chamber ensured an even distribution of the gases in the chamber. B) Gas-tight plant chambers with fern plants inside at the end of the incubation period. Aluminium foil was wrapped around the chambers during incubation with $\mathrm{CH}_{3} \mathrm{Cl}$ to reduce photosynthesis and microbial $\mathrm{CO}_{2}$ consumption during the labelling experiment. Sunlight entered the chambers through the clear top of the chamber.
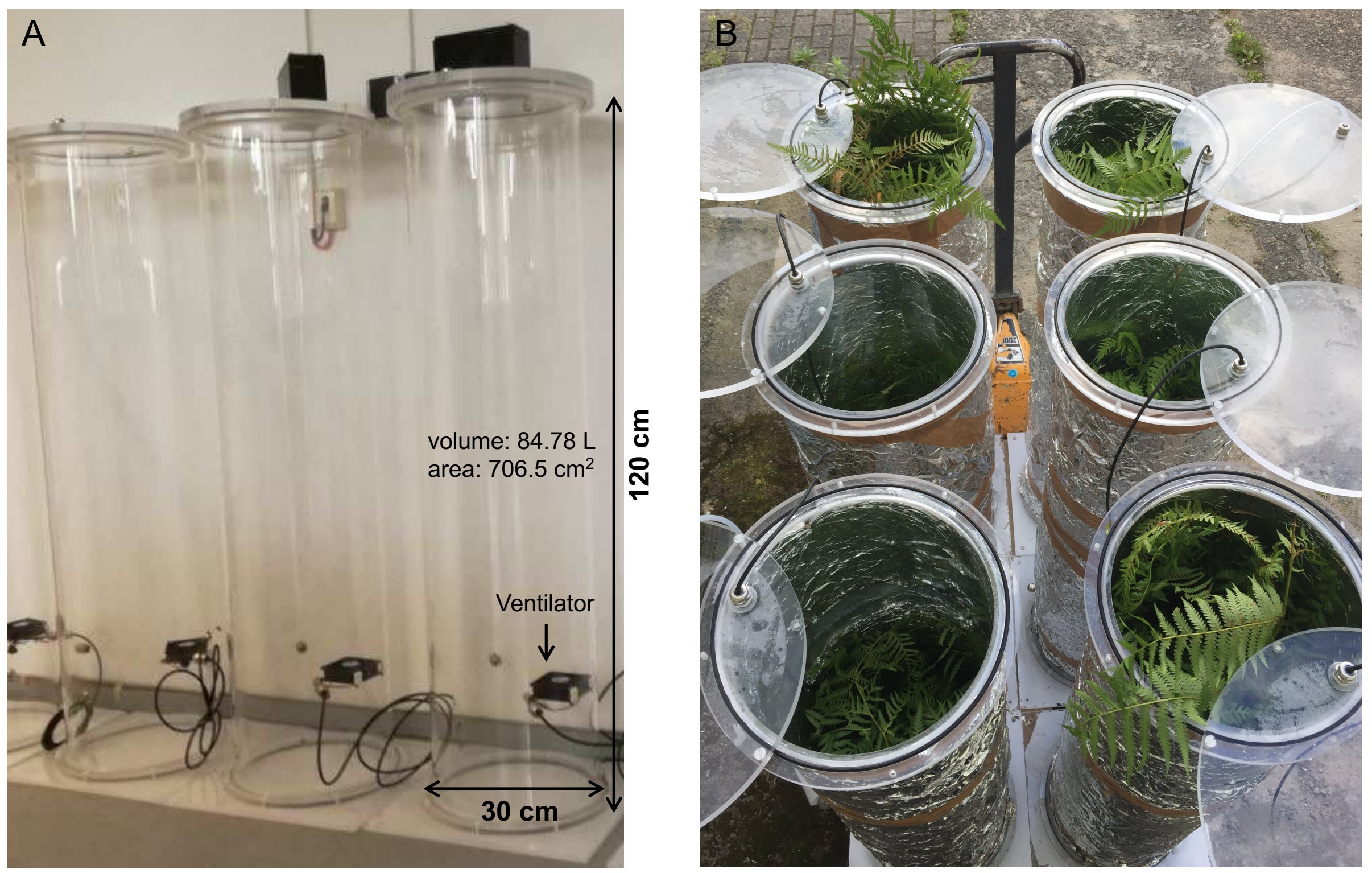
Supplementary Figure S2. Monitoring of the SIP-incubation of ferns. Incubations were carried out over 19 days with three biological replicated intact fern plants in gas-tight incubation chambers per tested condition. At the start of the SIP-incubation, $20 \mathrm{~mL} \mathrm{CH} 3 \mathrm{Cl}$ was added to the chambers (initial mixing ratio of $\sim 200 \mathrm{ppm}$ ) and degradation was monitored with GC-MS. At the end of each day, incubation chambers were opened and ventilated overnight. From day 2 of the incubation, $10 \mathrm{~mL} \mathrm{CH}_{3} \mathrm{Cl}$ was added to the chambers (initial mixing ratio of $\sim 100 \mathrm{ppm}$ ). (A) ${ }^{13} \mathrm{C}$-labelled $\mathrm{CH}_{3} \mathrm{Cl}$, and $(B){ }^{12} \mathrm{C}$-labelled $\mathrm{CH}_{3} \mathrm{Cl}$. Red arrows indicate point of $\mathrm{CH}_{3} \mathrm{Cl}$ addition.

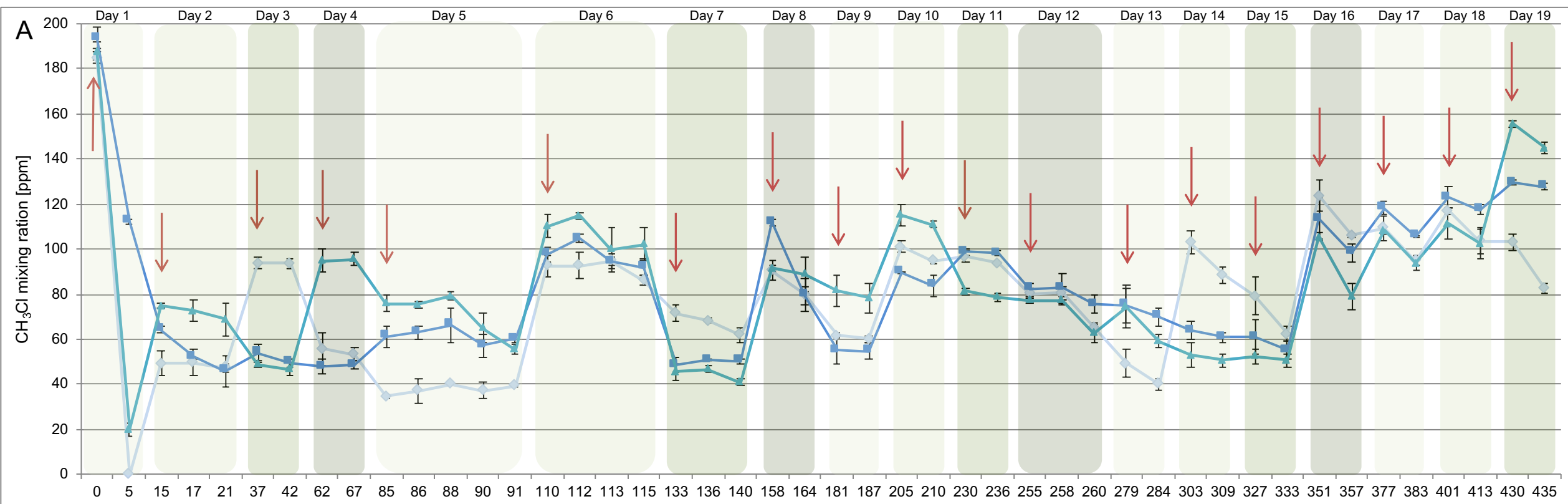

Time $[\mathrm{h}]$

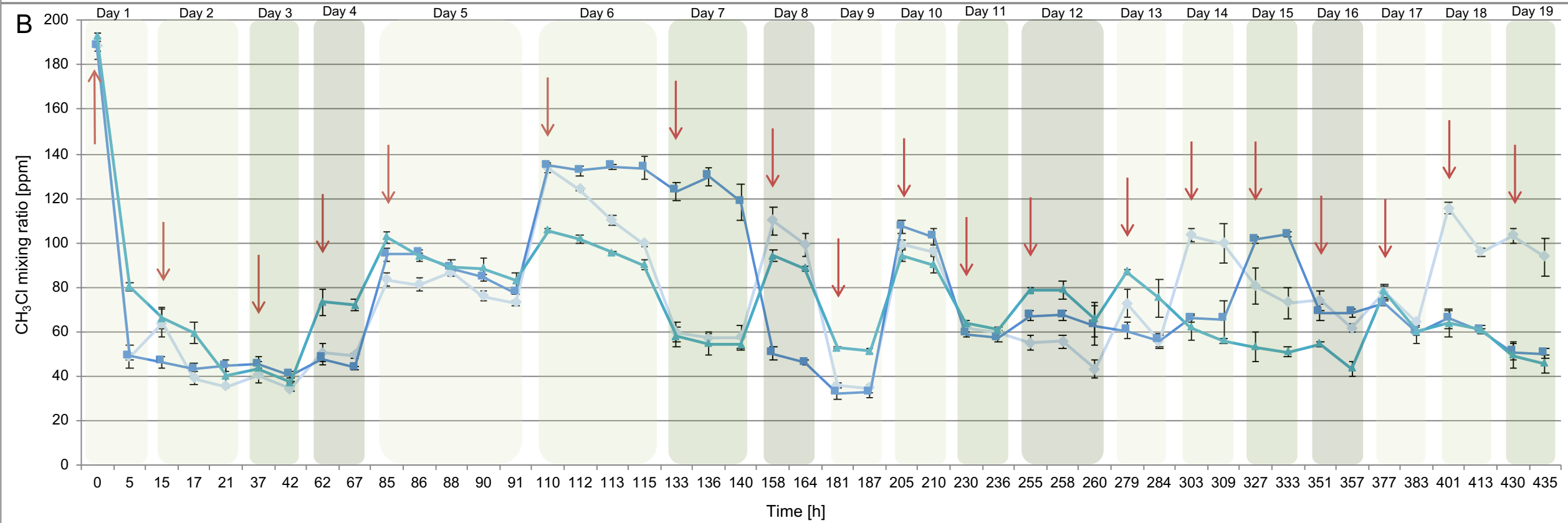


Supplementary Figure S3. Analysis of carbon mass fraction (C \%) and differential stable carbon isotope ratio $\left(\delta^{13} \mathrm{C}\right.$ value) of fern leaves and washed leaf samples $\left(T_{\text {end }}\right.$ washed) via EA/IRMS. Stable isotope ratios $\left(\delta^{13} \mathrm{C}\right)$ are expressed in permil (\%o) relative to the international standard.

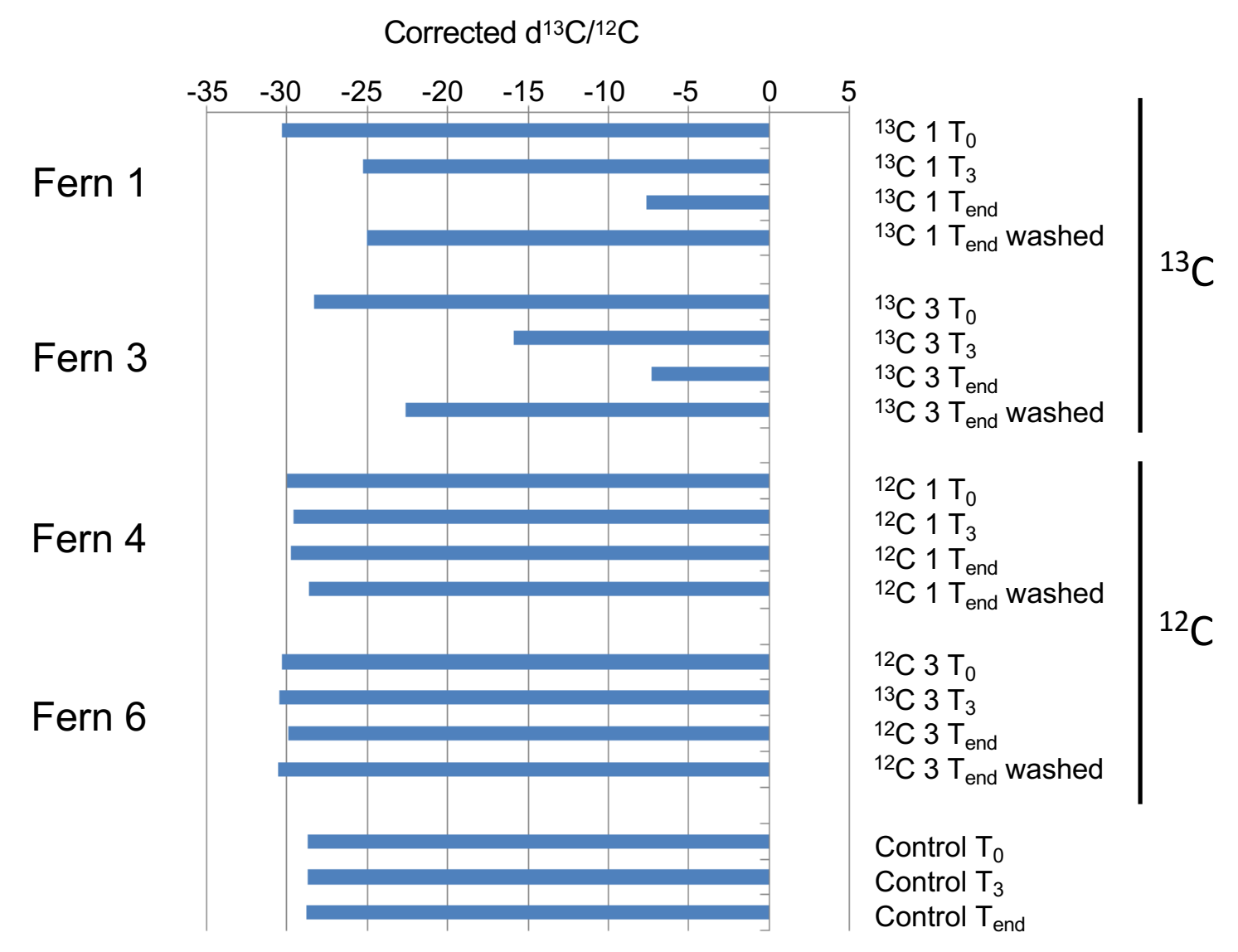


Supplementary Table S1. List of Metagenome Assembled Genomes (MAGs). Only MAGs with > $70 \%$ completeness and < $10 \%$

contamination are shown. MAGs highlighted in pink, yellow and green were used for further analysis, such as taxonomic classification,

metabolic reconstruction and/or pan-genomics. Single and co-assembly refer to processed reads assembled with MEGAHIT v.1.2.9 [60] once, and with an additional co-assembly of leaf and leaf wash metagenomes, respectively.

\begin{tabular}{|c|c|c|c|c|c|c|c|c|c|c|c|c|c|c|c|}
\hline 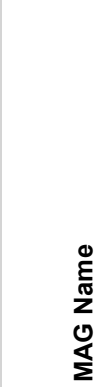 & 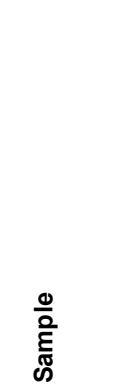 & 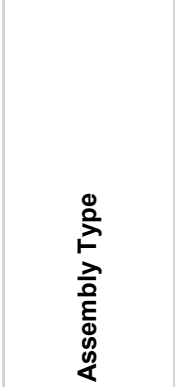 & 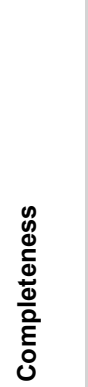 & 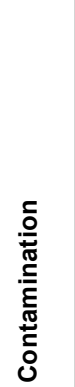 & U & $\begin{array}{l}\text { D } \\
\text { o } \\
0 \\
0\end{array}$ & 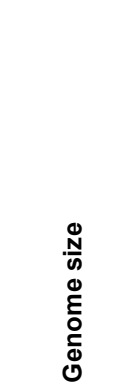 & $\begin{array}{l}\mathscr{0} \\
\stackrel{0}{E} \\
\stackrel{0}{0} \\
\dot{0} \\
\#\end{array}$ & 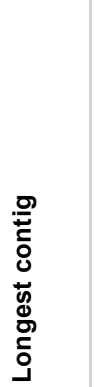 & 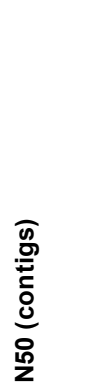 & 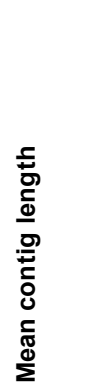 & 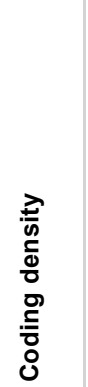 & 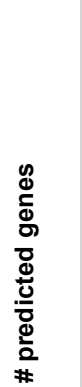 & 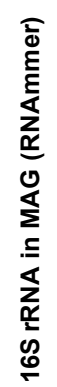 & 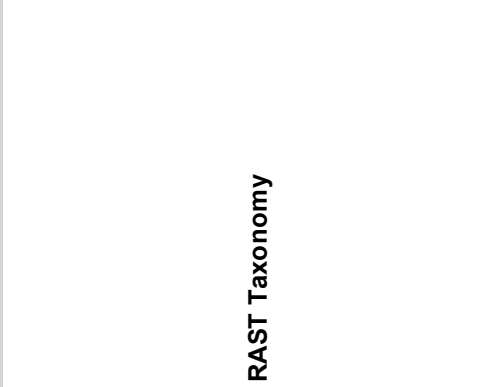 \\
\hline \multicolumn{2}{|c|}{ Fern $\mathrm{CH} 3 \mathrm{CI}$ SILEAF } & Co-Assembly & 74.1 & 6.9 & 0.69 & 0.01 & $2,589,893$ & 422 & 26327 & 6979 & 6137 & 0.92 & 2859 & no & Brevundimonas sp BAL3 \\
\hline \multicolumn{2}{|c|}{ Fern $\mathrm{CH} 3 \mathrm{Cl} \mathrm{SI}$ LEAF } & Co-Assembly & 74.7 & 1.6 & 0.62 & 0.02 & $3,566,997$ & 945 & 26720 & 4942 & 3775 & 0.89 & 3645 & no & Burkholderia mallei ATCC 23344 \\
\hline \multicolumn{2}{|c|}{ Fern $\mathrm{CH} 3 \mathrm{CI}$ SI LEAF } & Co-Assembly & 76.2 & 2.1 & 0.62 & 0.02 & $3,727,886$ & 1008 & 31300 & 4829 & 3698 & 0.89 & 3858 & no & Burkholderia mallei ATCC 23344 \\
\hline \multicolumn{2}{|c|}{ Fern $\mathrm{CH} 3 \mathrm{CI}$ SI LEAF } & Single & 86.2 & 4.1 & 0.70 & 0.01 & $3,121,099$ & 234 & 72936 & 16915 & 13338 & 0.91 & 3124 & no & Clavibacter michiganensis \\
\hline \multicolumn{2}{|c|}{ Fern $\mathrm{CH} 3 \mathrm{Cl} \mathrm{SI}$ LEAF } & Single & 87.5 & 3.0 & 0.74 & 0.02 & $2,895,226$ & 400 & 49341 & 10204 & 7238 & 0.91 & 3124 & no & Clavibacter michiganensis \\
\hline \multicolumn{2}{|c|}{ Fern $\mathrm{CH} 3 \mathrm{CI}$ SI LEAF } & Co-Assembly & 78.4 & 2.0 & 0.73 & 0.01 & $3,206,454$ & 302 & 54365 & 12926 & 10617 & 0.93 & 3148 & no & Janibacter sp HTCC2649 \\
\hline \multicolumn{2}{|c|}{ Fern $\mathrm{CH} 3 \mathrm{CI}$ SI LEAF } & Single & 80.7 & 2.9 & 0.73 & 0.01 & $3,298,717$ & 320 & 49896 & 11919 & 10308 & 0.93 & 3230 & no & Janibacter sp HTCC2649 \\
\hline \multicolumn{2}{|c|}{ Fern $\mathrm{CH} 3 \mathrm{CI}$ SI LEAF } & Single & 85.7 & 4.5 & 0.73 & 0.01 & $3,667,181$ & 375 & 49896 & 11466 & 9779 & 0.92 & 3592 & no & Janibacter sp HTCC2649 \\
\hline \multicolumn{2}{|c|}{ Fern $\mathrm{CH} 3 \mathrm{CI}$ SI LEAF } & Co-Assembly & 76.4 & 6.4 & 0.74 & 0.02 & $5,175,864$ & 963 & 34258 & 6859 & 5375 & 0.92 & 5489 & no & Kineococcus radiotolerans SRS30216 \\
\hline \multirow{2}{*}{\multicolumn{2}{|c|}{ Fern $\mathrm{CH} 3 \mathrm{CI}$ SI LEAF }} & Co-Assembly & 81.6 & 4.8 & 0.74 & 0.01 & $2,633,679$ & 435 & 32366 & 8104 & 6054 & 0.91 & 2911 & no & marine actinobacterium PHSC20C1 \\
\hline & Fern $\mathrm{CH} 3 \mathrm{Cl}$ SI LEAF & Co-Assembly & 78.1 & 7.3 & 0.70 & 0.01 & $3,454,154$ & 251 & 66164 & 18012 & 13762 & 0.91 & 3403 & no & marine actinobacterium PHSC20C1 \\
\hline \multicolumn{2}{|c|}{ Fern $\mathrm{CH} 3 \mathrm{CI}$ SI LEAF } & Co-Assembly & 79.4 & 1.6 & 0.72 & 0.02 & $3,437,766$ & 460 & 39543 & 9299 & 7473 & 0.92 & 3693 & no & Methylobacterium extorquens PA1 \\
\hline \multicolumn{2}{|c|}{ Fern $\mathrm{CH} 3 \mathrm{CI}$ SI LEAF } & Co-Assembly & 73.9 & 7.1 & 0.70 & 0.01 & $3,599,730$ & 301 & 42665 & 13382 & 11959 & 0.87 & 3627 & no & Methylobacterium extorquens PA1 \\
\hline \multicolumn{2}{|c|}{ Fern $\mathrm{CH} 3 \mathrm{CI}$ SI LEAF } & Single & 81.5 & 3.7 & 0.71 & 0.02 & $3,823,638$ & 420 & 71582 & 12689 & 9104 & 0.88 & 3909 & no & Methylobacterium radiotolerans JCM 2831 \\
\hline \multicolumn{2}{|c|}{ Fern $\mathrm{CH} 3 \mathrm{CI}$ SI LEAF } & Co-Assembly & 71.6 & 7.3 & 0.74 & 0.02 & $3,066,080$ & 562 & 27103 & 6693 & 5456 & 0.93 & 3233 & no & Nocardioides sp JS614 \\
\hline \multicolumn{2}{|c|}{ Fern $\mathrm{CH} 3 \mathrm{CI} \mathrm{SI}$ LEAF } & Co-Assembly & 80.8 & 10.0 & 0.72 & 0.01 & $3,692,543$ & 345 & 51678 & 11824 & 10703 & 0.92 & 3711 & yes & Propionibacterium acnes KPA171202 \\
\hline \multicolumn{2}{|c|}{ Fern $\mathrm{CH} 3 \mathrm{CI}$ SI LEAF } & Co-Assembly & 85.0 & 2.2 & 0.65 & 0.01 & $3,978,621$ & 509 & 49156 & 9622 & 7817 & 0.93 & 4150 & no & Rhodococcus jostii RHA1 \\
\hline \multicolumn{2}{|c|}{ Fern $\mathrm{CH} 3 \mathrm{CI}$ SI LEAF } & Single & 80.4 & 6.9 & 0.65 & 0.01 & $3,912,515$ & 992 & 24370 & 4591 & 3944 & 0.93 & 4414 & no & Rhodococcus jostii RHA1 \\
\hline \multicolumn{2}{|c|}{ Fern $\mathrm{CH} 3 \mathrm{CI}$ SI LEAFWASH } & Co-Assembly & 76.2 & 2.1 & 0.62 & 0.02 & $3,727,886$ & 1008 & 31300 & 4829 & 3698 & 0.89 & 3858 & no & Burkholderia mallei ATCC 23344 \\
\hline \multicolumn{2}{|c|}{ Fern $\mathrm{CH} 3 \mathrm{CI}$ SI LEAFWASH } & Co-Assembly & 81.7 & 9.9 & 0.62 & 0.02 & $4,717,577$ & 1629 & 26720 & 3751 & 2896 & 0.88 & 5196 & no & Burkholderia mallei ATCC 23344 \\
\hline \multicolumn{2}{|c|}{ Fern $\mathrm{CH} 3 \mathrm{CI}$ SI LEAFWASH } & Single & 73.3 & 1.3 & 0.62 & 0.02 & $3,273,165$ & 804 & 27709 & 5203 & 4071 & 0.89 & 3278 & no & Burkholderia mallei ATCC 23344 \\
\hline \multicolumn{2}{|c|}{ Fern $\mathrm{CH} 3 \mathrm{CI}$ SI LEAFWASH } & Co-Assembly & 76.2 & 4.3 & 0.74 & 0.02 & $2,212,892$ & 342 & 32366 & 9008 & 6470 & 0.91 & 2428 & no & Clavibacter michiganensis \\
\hline \multicolumn{2}{|c|}{ Fern $\mathrm{CH} 3 \mathrm{CI}$ SI LEAFWASH } & Co-Assembly & 86.8 & 8.1 & 0.73 & 0.01 & $3,544,565$ & 356 & 54365 & 12722 & 9957 & 0.92 & 3518 & no & Janibacter sp HTCC2649 \\
\hline \multicolumn{2}{|c|}{ Fern $\mathrm{CH} 3 \mathrm{CI}$ SI LEAFWASH } & Co-Assembly & 70.2 & 8.5 & 0.70 & 0.01 & $3,366,239$ & 256 & 66164 & 18000 & 13149 & 0.92 & 3318 & no & marine actinobacterium $\mathrm{PHSC} 20 \mathrm{C} 1$ \\
\hline Fern $\mathrm{CH}_{3}$ & AFWASH & Co-Assembly & 79.6 & 1.2 & 0.72 & 0.02 & $3,413,711$ & 456 & 39543 & 9410 & 7486 & 0.92 & 3656 & no & Methylobacterium extorquens PA1 \\
\hline Fern $\mathrm{CH}_{3}^{3}$ & AFWASH & Single & 82.8 & 6.6 & 0.74 & 0.02 & $3,222,653$ & 632 & 24538 & 6100 & 5099 & 0.92 & 3450 & no & Nocardioides sp JS614 \\
\hline Fern $\mathrm{CH}_{3}$ & AFWASH & Co-Assembly & 74.2 & 5.4 & 0.72 & 0.01 & $3,118,906$ & 275 & 54326 & 12680 & 11341 & 0.92 & 3111 & yes & Propionibacterium acnes KPA171202 \\
\hline Fern $\mathrm{CH}_{3}^{3}$ & AFWASH & Single & 74.9 & 1.3 & 0.62 & 0.02 & $3,393,326$ & 849 & 31300 & 5079 & 3997 & 0.89 & 3424 & no & Ralstonia solanacearum GMI1000 \\
\hline Fern $\mathrm{CH}_{3}$ & AFWASH & Co-Assembly & 86.6 & 2.6 & 0.65 & 0.01 & $4,120,025$ & 543 & 49156 & 9324 & 7588 & 0.93 & 4319 & no & Rhodococcus jostii RHA1 \\
\hline Fern $\mathrm{CH}_{3}$ & & Single & 72.9 & 3.8 & 0.71 & 0.02 & $2,231,874$ & 545 & 23284 & 4891 & 4095 & 0.92 & 2647 & no & Ammonifex degensii KC4 \\
\hline Fern $\mathrm{CH}_{3}$ & & Single & 74.3 & 2.2 & 0.67 & 0.02 & $3,755,866$ & 949 & 17944 & 4419 & 3958 & 0.92 & 4334 & no & Mycobacterium tuberculosis H37Rv \\
\hline Fern $\mathrm{CH}_{3}^{3}$ & & Single & 73.4 & 1.4 & 0.65 & 0.02 & $2,344,994$ & 487 & 23872 & 5961 & 4815 & 0.93 & 2607 & yes & Rhodoferax ferrireducens DSM 15236 \\
\hline Fern $\mathrm{CH}_{3}$ & & Single & 81.2 & 4.4 & 0.65 & 0.01 & $7,667,279$ & 945 & 67204 & 9821 & 8114 & 0.91 & 7236 & no & Sorangium cellulosum So ce 56 \\
\hline Fern $\mathrm{CH}_{3}$ & & Single & 83.8 & 9.2 & 0.65 & 0.01 & $8,685,556$ & 1130 & 69346 & 9351 & 7686 & 0.91 & 8550 & no & Sorangium cellulosum So ce 56 \\
\hline
\end{tabular}


Supplementary Table S2. List of Methylobacterium / Methylorubrum genomes used for pan-genomics.

\begin{tabular}{|c|c|c|c|c|c|}
\hline Genus & Source & $\begin{array}{l}\text { INSDC No.I } \\
\text { Accession No. }\end{array}$ & $\begin{array}{l}\text { Genome size } \\
\text { [bp] }\end{array}$ & $\begin{array}{l}\text { No. of predicted } \\
\text { genes }\end{array}$ & Reference \\
\hline Methylobacterium aquaticum MA-22A & Moss & AP014704 & $7,557,960$ & 6,993 & [118] \\
\hline Methylobacterium gossipiicola Gh-105 & Cotton phyllosphere & FOPM01000046 & $4,524,655$ & 4,224 & [82] \\
\hline Methylobacterium oryzae CBMB20 & Rice phyllosphere & СР003811 & $6,286,629$ & 5,795 & [113] \\
\hline Methylobacterium phyllosphaerae CBMB27 & Rice phyllosphere & СР015367 & $6,203,749$ & 5,820 & [89] \\
\hline Methylobacterium phyllostachyos BL47 & Bamboo phyllosphere & FNHS01000044 & $6,015,046$ & 5,790 & [119] \\
\hline Methylobacterium platani JCM 14648 & Platanus orientalis phyl. & JXOD01000099 & $6,770,243$ & 6,358 & {$[120]$} \\
\hline Methylobacterium platani SE3.6 & Rice seed & JTHG01000099 & $6,930,824$ & 6,635 & [121] \\
\hline Methylobacterium pseudosasicola BL36 & Bamboo phyllosphere & FOTK01000093 & $6,845,277$ & 6,795 & [119] \\
\hline Methylobacterium sp. WSM2598 & Listia bainesii nodule & KB900613 & $8,130,841$ & 7,551 & [122] \\
\hline Methylobacterium variabile DSM 16961 & Aquatic environment & LABY01000099 & $7,432,100$ & 7,183 & [123] \\
\hline Methylorubrum extorquens TK 0001 & Soil & LT962688 & $5,715,512$ & 5,435 & [124] \\
\hline Methylorubrum populi BJ001 & Poplar tree tissue & NC_010725 & $5,848,997$ & 5,464 & [125] \\
\hline Methylorubrum salsuginis CGMCC 1.6474 & Seawater & FOSV01000046 & $5,323,773$ & 5,012 & [126] \\
\hline Metagenomic bin Fern $\mathrm{CH}_{3} \mathrm{Cl}$ SIP LEAF bin s3 & $\begin{array}{l}\text { Cyathea australis } \\
\text { phyllosphere }\end{array}$ & SAMN17394138 & $3,823,638$ & 3,909 & This study \\
\hline Metagenomic bin Fern $\mathrm{CH}_{3} \mathrm{Cl}$ SIP LEAF bin co1 & $\begin{array}{l}\text { Cyathea australis } \\
\text { phyllosphere }\end{array}$ & SAMN17394139 & $3,437,766$ & 3,693 & This study \\
\hline
\end{tabular}




\section{Supplementary Table S3. Gene presence in labeled MAGs.}

\begin{tabular}{|c|c|c|c|c|c|c|c|}
\hline \multicolumn{2}{|c|}{ Pathway, gene and gene product } & 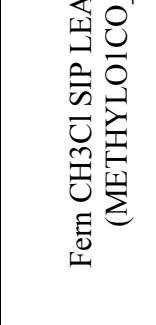 & 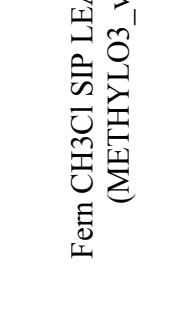 & 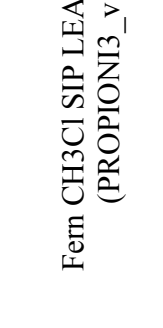 & 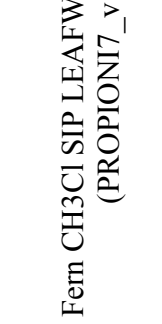 & & \\
\hline \multicolumn{8}{|c|}{ methanol oxidation } \\
\hline$m x a F I$ & methanol dehydrogenase (cytochrome c) subunits [EC:1.1.2.7] & nd $[\mathrm{b}]$ & $\begin{array}{l}510001 \\
210010 \text {-like }\end{array}$ & nd & nd & nd & nd \\
\hline$x o x F$ & lanthanide-dependent methanol dehydrogenase [EC:1.1.2.10] & nd & 2580029 & nd & nd & nd & nd \\
\hline $\begin{array}{l}\operatorname{exaF}(A) \\
(m d h 2)\end{array}$ & $\begin{array}{l}\text { PQQ-dependent methanol/ethanol dehydrogenase precursor, lanthanide- } \\
\text { containing [EC:1.1.1.244, EC:1.1.99.-] }\end{array}$ & nd & $\begin{array}{l}210010-\text { like } \\
1870009\end{array}$ & nd & nd & nd & nd \\
\hline \multicolumn{8}{|c|}{ methane oxidation to methanol } \\
\hline$m m o X Y Z$ & methane monooxygenase component A chains [EC:1.14.13.25] & nd & nd & nd & nd & nd & nd \\
\hline pmoABC & methane/ammonia monooxygenase subunits & nd & nd & nd & & nd & \\
\hline \multicolumn{8}{|c|}{ methylamine oxidation } \\
\hline mauAB & methylamine dehydrogenase [EC:1.4.99.3] subunits & nd & nd & nd & nd & nd & nd \\
\hline gmaS & $\gamma$-glutamylmethylamide synthase [EC:6.3.4.12] & nd & nd & nd & nd & nd & nd \\
\hline$m g d A B C D$ & $\mathrm{~N}$-methylglutamate dehydrogenase [EC:1.5.99.5] subunits & $\begin{array}{l}1080002-3 \\
1080006\end{array}$ & nd & nd & nd & nd & nd \\
\hline$m g s A B C$ & $\mathrm{~N}$-methylglutamate synthase [EC:2.4.2.-] subunits & nd & nd & $3030003-5$ & $2420003-5$ & nd & nd \\
\hline \multicolumn{8}{|c|}{ C1 transfer reactions: primary oxidation } \\
\hline fae & 5,6,7,8-tetrahydromethanopterin hydro-lyase [EC:4.2.1.147] & nd & $\begin{array}{l}3420072 \\
1110002 \\
1540002\end{array}$ & nd & nd & nd & nd \\
\hline $\begin{array}{l}m t d B \\
(m d t A)\end{array}$ & methylene H4MPT-dehydrogenase [EC:1.5.1.-] & nd & 2750003 & nd & nd & nd & nd \\
\hline mch & methenyltetrahydromethanopterin cyclohydrolase [EC:3.5.4.27] & nd & 2750004 & nd & nd & nd & nd \\
\hline$f h c A B C D$ & formyltransferase/hydrolase complex Fhc & nd & 3210016_19 & nd & nd & nd & nd \\
\hline$f c h$ & methenyl H4F-cyclohydrolase [EC:3.5.4.9] & nd & 3410009 & nd & nd & nd & nd \\
\hline
\end{tabular}




\begin{tabular}{|c|c|c|c|c|c|c|c|}
\hline $\begin{array}{l}m t d A \\
g l y A\end{array}$ & $\begin{array}{l}\text { methylene H4MPT-dehydrogenase/methylene H4F-dehydrogenase } \\
\text { [EC:1.5.1.5, 1.5.1.-] } \\
\text { glycine hydroxymethyltransferase [EC:2.1.2.1] (Ser cycle) }\end{array}$ & $\begin{array}{l}\text { nd } \\
4570002\end{array}$ & $\begin{array}{l}3410008 \\
2340008\end{array}$ & $\begin{array}{l}\text { nd } \\
\text { nd }\end{array}$ & $\begin{array}{l}\text { nd } \\
\text { nd }\end{array}$ & $\begin{array}{l}\text { nd } \\
6950008\end{array}$ & $\begin{array}{l}\text { nd } \\
8320007\end{array}$ \\
\hline \multicolumn{8}{|c|}{ C1 transfer reactions: primary demethylation $\mathrm{H} 4 \mathrm{~F}$-linked } \\
\hline metF2 & methylenetetrahydrofolate reductase [EC:1.5.1.20] & nd & nd & nd & nd & nd & nd \\
\hline folD & $\begin{array}{l}\text { methylene H4F-dehydrogenase/methenyl H4F-cyclohydrolase } \\
\text { [EC:1.5.1.5 3.5.4.9] }\end{array}$ & 3800010 & nd & 990020 & 850020 & 7530008 & 8980008 \\
\hline $\operatorname{pur} U$ & formyltetrahydrofolate deformylase [EC:3.5.1.10] & 4300009 & nd & nd & nd & 6950006 & 8320005 \\
\hline$f d h$ & S-(hydroxymethyl)glutathione dehydrogenase [EC:1.1.1.284] & 4420002 & 3990004 & $\begin{array}{l}10005 \\
2770014\end{array}$ & $\begin{array}{l}10005 \\
2260014\end{array}$ & nd & nd \\
\hline fhs $(f t f L)$ & formate--tetrahydrofolate ligase [EC:6.3.4.3] & 910006 & 1050006 & nd & nd & nd & nd \\
\hline \multicolumn{8}{|c|}{ ethylmalonyl-CoA pathway (EMCP) } \\
\hline $\operatorname{sgaA}$ & serine--glyoxylate aminotransferase [EC:2.6.1.45] (Ser cycle) & 1410013 & 3410006 & nd & nd & nd & nd \\
\hline hprA & glycerate dehydrogenase [EC:1.1.1.29] (Ser cycle) & nd & 3410007 & nd & nd & 2430007 & 2800007 \\
\hline gck & glycerate kinase [EC:1.1.1.81] (Ser cycle) & 4010001-like & 800010 & nd & nd & 8150004 & nd \\
\hline eno & enolase [4.2.1.11] (Ser cycle) & 1900007 & nd & 2600009 & 2100009 & 3610005 & 4190005 \\
\hline$p p c$ & phosphoenolpyruvate carboxylase [EC:4.1.1.31] (Ser cycle) & 1510001-like & 1700001 & nd & nd & 4820006 & 5610006 \\
\hline$m d h$ & malate dehydrogenase [EC:1.1.1.37] & 2680002 & & nd & nd & nd & nd \\
\hline$m t k A B$ & malate thiokinase [EC:6.2.1.9], large and small subunits (Ser cycle) & 2680003-like & $\begin{array}{l}3410010 \\
3410011\end{array}$ & $\begin{array}{l}\text { 990013-like } \\
\text { 990014-like }\end{array}$ & $\begin{array}{l}\text { 850013-like } \\
850014-\text { like }\end{array}$ & nd & nd \\
\hline$m c l$ & L-malyl-CoA/beta-methylmalyl-CoA lyase [EC:4.1.3.24] & 680002 & 1700002 & nd & nd & nd & nd \\
\hline phaA & beta-ketothiolase [EC:2.3.1.16] & 2150009 & 1590015 & 1410005 & 1180005 & 3350025 & 3900027 \\
\hline phaB & acetoacetyl-CoA reductase [EC:1.1.1.36] & 2150007 & 1590014 & nd & nd & nd & nd \\
\hline $\operatorname{croR}$ & crotonase [EC:4.2.1.55] & nd & 1430007 & nd & nd & nd & nd \\
\hline$c c r$ & crotonyl-CoA reductase [EC:1.3.1.85] & nd & 660006 & nd & nd & nd & nd \\
\hline ecm (meaA) & ethylmalonyl-CoA mutase [EC:5.4.99.63] & 2740001 & 3140013 & nd & nd & nd & nd \\
\hline msd & methylsuccinyl-CoA dehydrogenase [EC:1.3.8.4] & 4310001 & 3350010 & nd & nd & nd & nd \\
\hline med & methylsuccinyl-CoA dehydrogenase $\quad$ [EC: 1.3 .8 .4$]$ & 4310001 & 3350010 & nd & nd & nd & nd \\
\hline$p c c A B$ & propionyl-CoA carboxylase [EC:6.4.1.3] alpha and beta subunits & $\begin{array}{l}3140006 \\
3770008\end{array}$ & $\begin{array}{l}2280001 \\
100012\end{array}$ & 1360011 & 1160011 & 4470013 & 5200012 \\
\hline meaB & ethylmalonyl-CoA mutase accessory protein & nd & nd & 1410004 & 2140009 & $\begin{array}{l}3520009 \\
4590001\end{array}$ & 4090009 \\
\hline$m c m A B$ & methylmalonyl-CoA mutase [EC:5.4.99.2] alpha subunit & $\begin{array}{l}1190003 \\
2730001\end{array}$ & $\begin{array}{l}2530011 \\
2880016\end{array}$ & 2840002 & $\begin{array}{l}2140010 \\
2290002\end{array}$ & 4180008 & $\begin{array}{l}4880008 \\
8690001\end{array}$ \\
\hline$s d h A B C D$ & succinate dehydrogenase [EC:1.-.-.-], flavoprotein subunit & $\begin{array}{l}2770004-6 \\
2970003\end{array}$ & 160015 & nd & nd & $\begin{array}{l}5810004-5 \\
\text { like }\end{array}$ & $\begin{array}{l}6080002-3 \\
6900005-6\end{array}$ \\
\hline fumC & fumarate hydratase [EC:4.2.1.2] & 2860002 & & 3430003 & 2740003 & 950003 & 1080003 \\
\hline \multicolumn{8}{|c|}{ formaldehyde oxidation (glutathione-dependent) } \\
\hline$g f a$ & glutathione-dependent formaldehyde-activating enzyme [EC:4.4.1.22] & 4510002 & nd & nd & nd & $\begin{array}{l}2640010 \\
1400003\end{array}$ & $\begin{array}{l}3050009 \\
1560003\end{array}$ \\
\hline frmA & $\begin{array}{l}\text { alcohol dehydrogenase class III/glutathione-dependent formaldehyde } \\
\text { dehydrogenase }[1.1 .1 .1,1.1 .1 .284]\end{array}$ & 470005 & 770022-like & nd & nd & 2580006 & 2980006 \\
\hline
\end{tabular}




\begin{tabular}{|c|c|c|c|c|c|c|c|}
\hline$f d h$ & S-(hydroxymethyl)glutathione dehydrogenase [EC:1.1.1.284] & 4420002 & 3990004 & $\begin{array}{l}10005 \\
2770014\end{array}$ & $\begin{array}{l}10005 \\
2260014\end{array}$ & nd & nd \\
\hline \multicolumn{8}{|c|}{ glycine cleavage system (GCP) } \\
\hline$g c v P$ & PLP-dependent glycine dehydrogenase [EC:1.4.4.2] & nd & nd & 2910006 & 2340006 & \begin{tabular}{|l|l|}
1220003 \\
9080023
\end{tabular} & $\begin{array}{l}10910023 \\
1370003\end{array}$ \\
\hline$g c v H$ & decarboxyating, aminomethyltransferase protein $\mathrm{H}$ [EC:1.4.4.2,2.1.2.10] & 440029 & nd & 2910001 & 2340001 & 3880005 & 4390005 \\
\hline$g c v T$ & $\begin{array}{l}\text { aminomethyltransferase tetrahydrofolate-dependent protein } \mathrm{T} \\
{[\mathrm{EC}: 2.1 .2 .10]}\end{array}$ & nd & nd & 320013 & 290013 & 3770004 & 4390004 \\
\hline
\end{tabular}

[a] Annotation and analysis of genomic content and features as described in the MaGe plateform [76, 77] (https://mage.genoscope.cns.fr/microscope/mage/).

[b] Nd, not detected 
Supplementary Table S4. List of enzymes that potentially use or produce halides in labeled ${ }^{13}$ C-MAGs.

\begin{tabular}{|c|c|c|c|c|c|c|c|c|c|c|c|c|}
\hline & Halogenase / dehalogenase [a & & & & & & & & MAGs & lated $[\mathbf{b}]$ & & \\
\hline $\mathrm{EC} \mathrm{\#}$ & Enzyme & $\stackrel{\dot{1}}{n}$ & 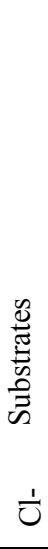 & \lrcorner & $\dot{1}$ & $\perp$ & 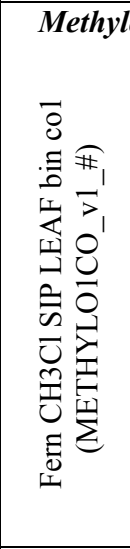 & 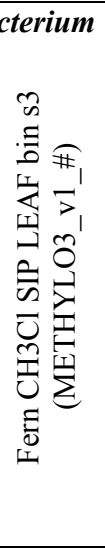 & 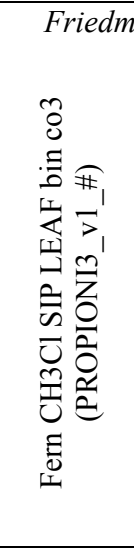 & 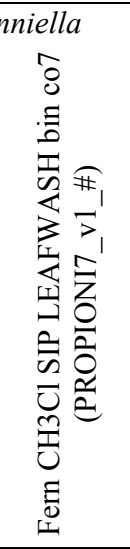 & 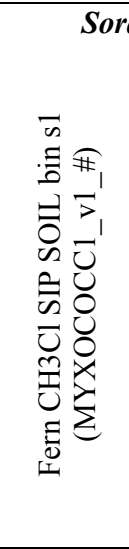 & 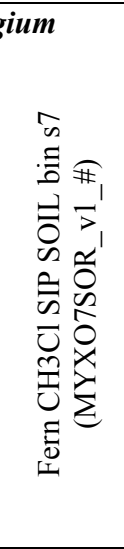 \\
\hline 1.10 .3 .2 & Laccase & & & $\mathrm{x}$ & & & nd & nd & nd & nd & nd & nd \\
\hline 1.11 .1 .10 & Chloride peroxidase & & $\mathrm{x}$ & & & & nd & nd & nd & nd & nd & nd \\
\hline 1.11 .1 .11 & L-ascorbate peroxidase & & & $\mathrm{x}$ & & & nd & nd & nd & nd & nd & nd \\
\hline 1.11 .1 .7 & Peroxidase & & & $\mathrm{x}$ & & & nd & nd & nd & nd & 370002 & 6050003 \\
\hline 1.11.1.8 & Iodide peroxidase & & & $\mathrm{x}$ & & & nd & nd & nd & nd & nd & nd \\
\hline $1.11 .1 . \mathrm{B} 2$ & $\begin{array}{l}\text { Chloride peroxidase, vanadium- } \\
\text { containing }\end{array}$ & $\mathrm{x}$ & $\mathrm{X}$ & & & & nd & nd & nd & nd & nd & nd \\
\hline 1.11 .2 .1 & Unspecific peroxygenase & $\mathrm{x}$ & & & & & nd & nd & nd & nd & nd & nd \\
\hline 1.11 .2 .2 & Myeloperoxidase & & $\mathrm{x}$ & & & & nd & nd & nd & nd & nd & nd \\
\hline 1.13 .11 .49 & Chlorite O2-lyase & & $\mathrm{x}$ & & $\mathrm{x}$ & & nd & nd & 1730007 & 1420007 & nd & nd \\
\hline 1.13 .11 .64 & 5-nitrosalicylate dioxygenase & & & & $\mathrm{x}$ & & nd & nd & nd & nd & nd & nd \\
\hline 1.14 .12 .13 & 2-halobenzoate 1,2-dioxygenase & & & & $\mathrm{x} \quad \mathrm{x}$ & $\mathrm{x}$ & nd & nd & nd & 0 & nd & nd \\
\hline 1.14 .13 .1 & Salicylate 1-monooxygenase & & & & & $\mathrm{x}$ & 2490006 & nd & nd & nd & nd & nd \\
\hline 1.14 .13 .22 & Cyclohexanone monooxygenase & & & $\mathrm{x}$ & & & nd & nd & nd & nd & nd & nd \\
\hline 1.14 .13 .50 & Pentachlorophenol monooxygenase & & & & $\mathrm{x}$ & $\mathrm{x}$ & nd & nd & nd & nd & nd & nd \\
\hline 1.14 .19 .49 & Tetracycline 7-halogenase & & $\mathrm{x}$ & & & & nd & nd & nd & nd & nd & nd \\
\hline 1.14 .19 .55 & $\begin{array}{l}\text { 4-hydroxybenzoate brominase } \\
\text { (decarboxylating) }\end{array}$ & $\mathrm{x}$ & & & & & nd & nd & nd & nd & nd & nd \\
\hline 1.14 .19 .56 & $\begin{array}{l}\text { 1H-pyrrole-2-carbonyl-[peptidyl- } \\
\text { carrier protein] chlorinase }\end{array}$ & & $\mathrm{x}$ & & & & nd & nd & nd & nd & nd & nd \\
\hline 1.14 .19 .57 & $\begin{array}{l}\text { 1H-pyrrole-2-carbonyl-[peptidyl- } \\
\text { carrier protein] brominase }\end{array}$ & $\mathrm{x}$ & & & & & nd & nd & nd & nd & nd & nd \\
\hline 1.14 .19 .58 & Tryptophan 5-halogenase & & $\mathrm{x}$ & & & & nd & nd & nd & nd & nd & nd \\
\hline 1.14 .19 .59 & Tryptophan 6-halogenase & $\mathrm{x}$ & $\mathrm{x}$ & & & & nd & nd & nd & nd & nd & nd \\
\hline 1.14.19.9 & Tryptophan 7-halogenase & $\mathrm{x}$ & $\mathrm{x}$ & & & & nd & nd & nd & nd & nd & nd \\
\hline 1.14 .20 .14 & Hapalindole-type alkaloid chlorinase & $\mathrm{x}$ & $\mathrm{x}$ & & & & nd & nd & nd & nd & nd & nd \\
\hline 1.21 .1 .1 & Iodotyrosine deiodinase & $\mathrm{x}$ & $\mathrm{x}$ & $\mathrm{x}$ & & $\mathrm{x}$ & nd & nd & nd & nd & nd & nd \\
\hline 1.21 .1 .2 & 2,4-dichlorobenzoyl-CoA reductase & & & & $\mathrm{x}$ & & nd & nd & nd & nd & nd & nd \\
\hline 1.21 .99 .3 & Thyroxine 5-deiodinase & & & $\mathrm{x}$ & & $\mathrm{x}$ & nd & nd & nd & nd & nd & nd \\
\hline 1.21 .99 .4 & Thyroxine 5'-deiodinase & & & $\mathrm{x}$ & & $\mathrm{x}$ & nd & nd & nd & nd & nd & nd \\
\hline 1.21.99.5 & $\begin{array}{l}\text { Tetrachloroethene reductive } \\
\text { dehalogenase }\end{array}$ & & $\mathrm{x}$ & & $\mathrm{x}$ & $\mathrm{x}$ & nd & nd & nd & nd & nd & nd \\
\hline 2.1.1.165 & Methyl-halide transferase & $\mathrm{x}$ & $\mathrm{x}$ & $\mathrm{x}$ & & & nd & nd & nd & nd & nd & nd \\
\hline 2.1 .1 .9 & thiol S-methyltransferase & $\mathrm{x}$ & $\mathrm{x}$ & & & & $\mathrm{nd}$ & $\mathrm{nd}$ & $\mathrm{nd}$ & $\mathrm{nd}$ & $\mathrm{nd}$ & nd \\
\hline
\end{tabular}




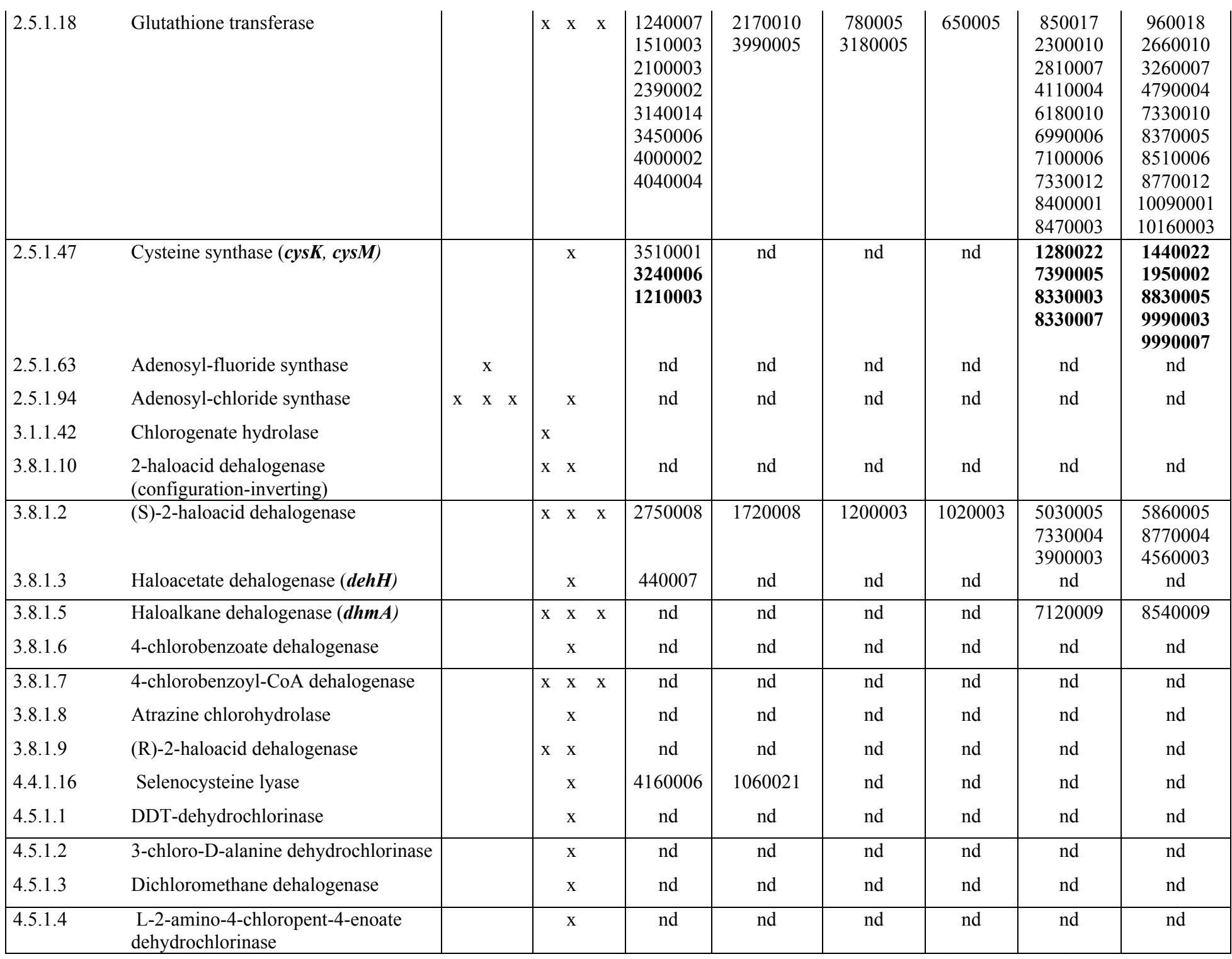

[a] According to the BRENDA database available at www.brenda-enzymes.org. Adapted from Table S1, a complete list of halogenases/dehalogenases [79]

[b] MAGs annotation protein label in MaGe platform. Names in bold when assigned gene names

[c] nd, not detected, MAGE automatic annotation 


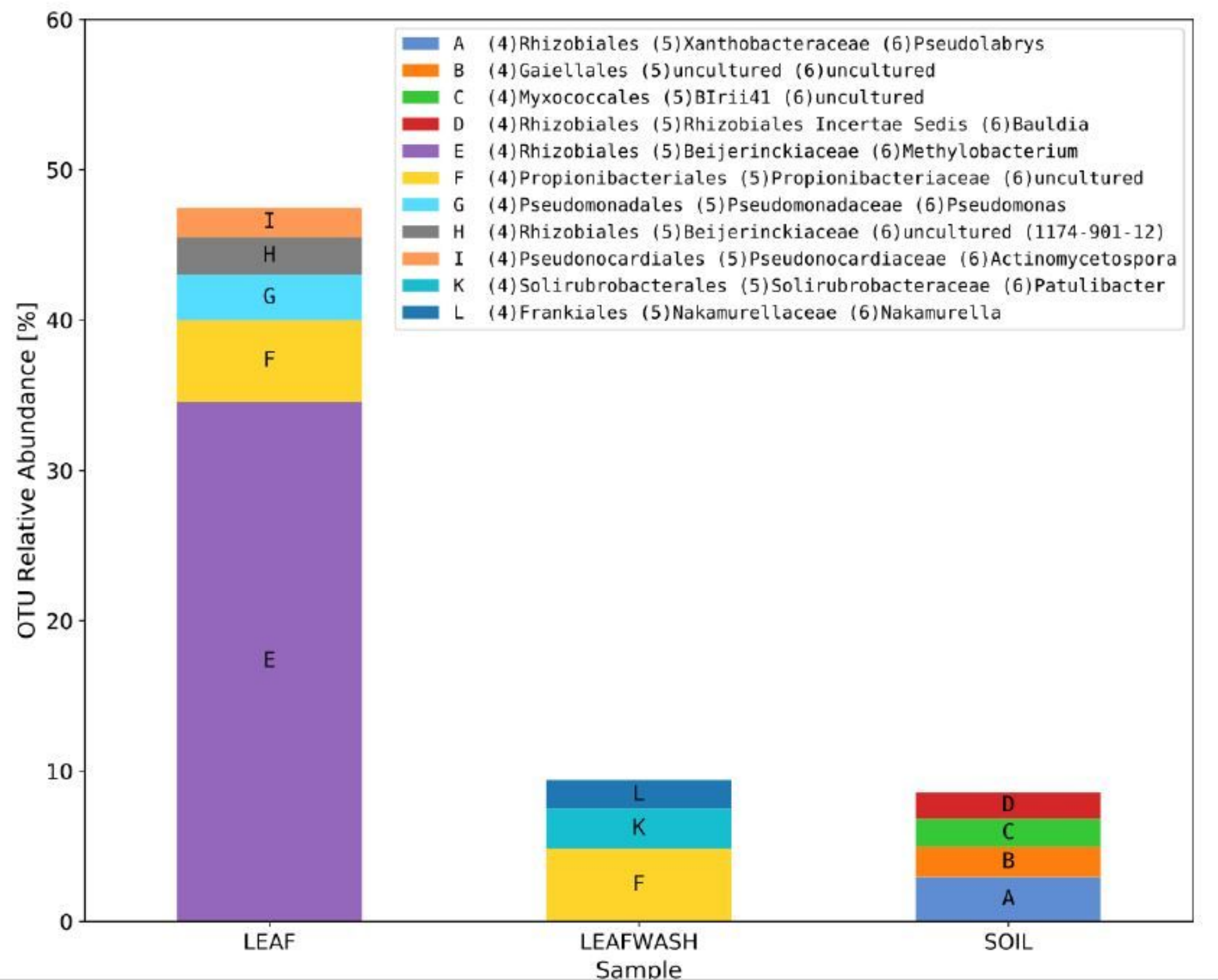

\section{Figure 1}

Relative abundance of 13C-labelled bacterial OTUs on genus level from fraction samples LEAF, LEAFWASH and SOIL. OTUs are classified as 'labelled' by the following criteria: 1) 13C-heavy >12Cheavy; 2) 13C-heavy > 13C-light; 3) 13C-[heavy-light] > 12C-[heavy-light]; 4) 13C[Heavy-Light] > threshold, with threshold $=0.005 \%$. The taxonomic affiliation of each labeled OTU is indicated at the family, order and genus levels (4-6, respectively), with a specific color and capital letter (see legend box). 

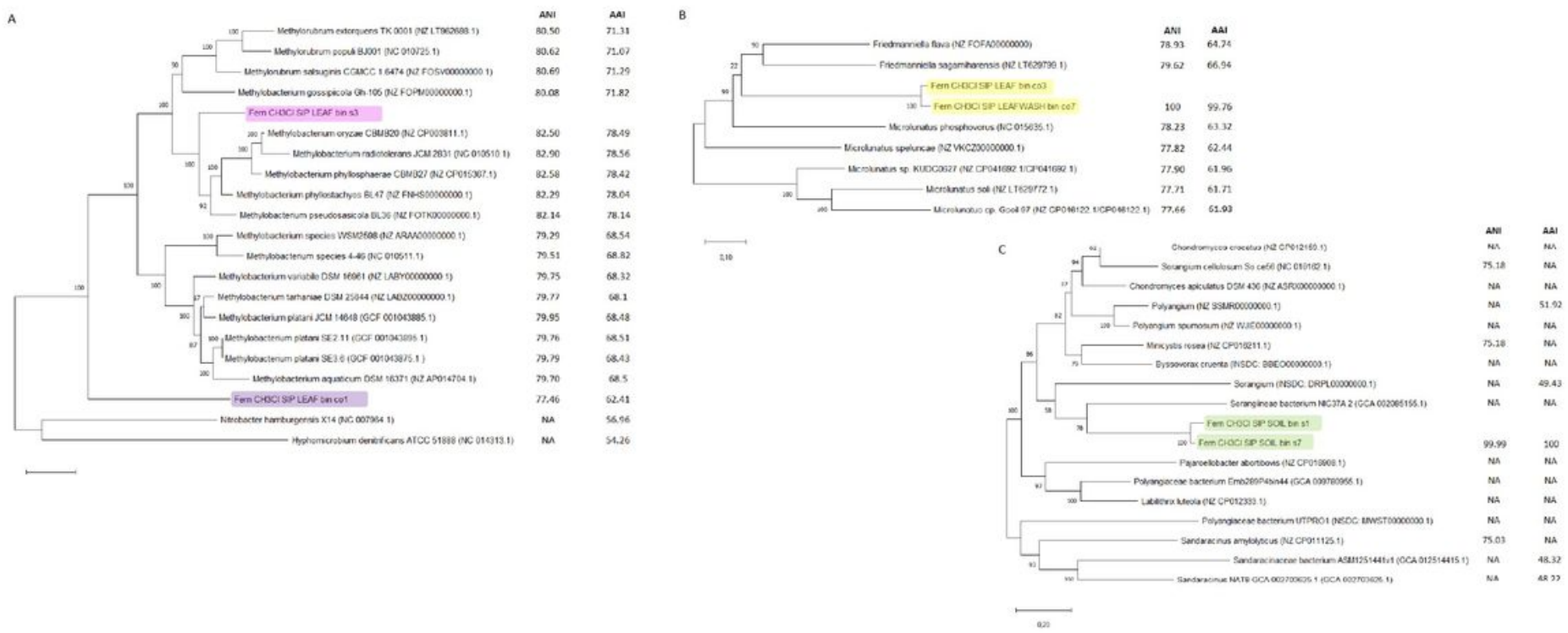

Figure 2

Maximum-likelihood phylogenetic trees showing the position of selected MAGs within tree of closely related reference genomes. Multiple sequence alignments of concatenated marker genes were constructed using PhyloPhIAn 3.0. Phylogenetic analysis was performed based on a matrix of pairwise distances estimated using the $\mathrm{LG}+\mathrm{F}+\mathrm{G}+\mathrm{I}$ model with 500 bootstrap replications. Numbers at branch nodes refer to bootstrap values. (A) Phylogenetic tree of Methylobacterium species. Two metagenomic bins isolated from the LEAF fraction were classified as Methylobacterium (marked in pink and purple) and were placed within 19 selected reference genomes of Alphaproteobacteria. Tree was annotated with ANI and AAI values in relation to 'Fern CH3CI SIP LEAF bin s3'. (B) Phylogenetic tree of Propionibacterium species. Two bins classified as related to Propionobacterium (marked in yellow) from fractions LEAF and LEAFWASH were placed in a tree with 7 selected reference genomes from Microlunatus and Friedmaniella. Annotated ANI and AAI values are in relation to 'Fern $\mathrm{CH} 3 \mathrm{CI}$ SIP LEAF bin co3'. (C) Phylogenetic tree of Myxococcales species. Two bins classified as related to Sorangium (marked in green) from fraction SOIL were placed in a tree with 16 reference genomes of of Deltaproteobacteria. Tree was annotated with ANI and AAI values in relation to 'Fern CH3CI SIP SOIL bin S1'; AAI values significantly under 50 and ANI values significantly under 70 were not computed and are annotated with NA. 
Figure 3.

Central carbon metabolism

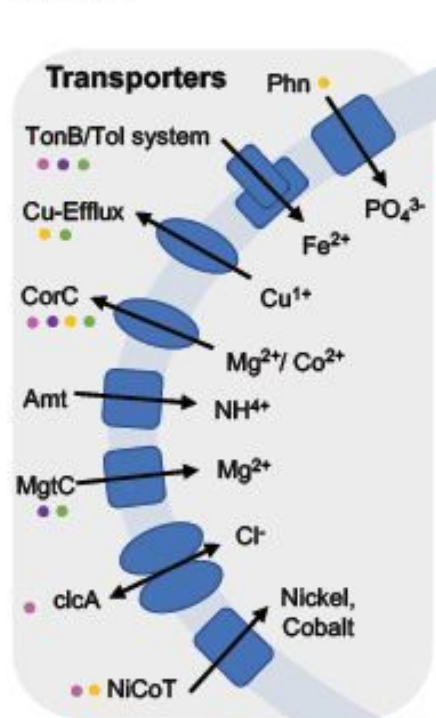

Stress response

- osmotic stress response

(osmoregulated periplasmic

glucans/ glycine betaine) .....

- superoxide dismutase (Fe, Cu$\mathrm{Zn})$..

- peroxidase, catalase *

- glutathione

- periplasmatic stress response

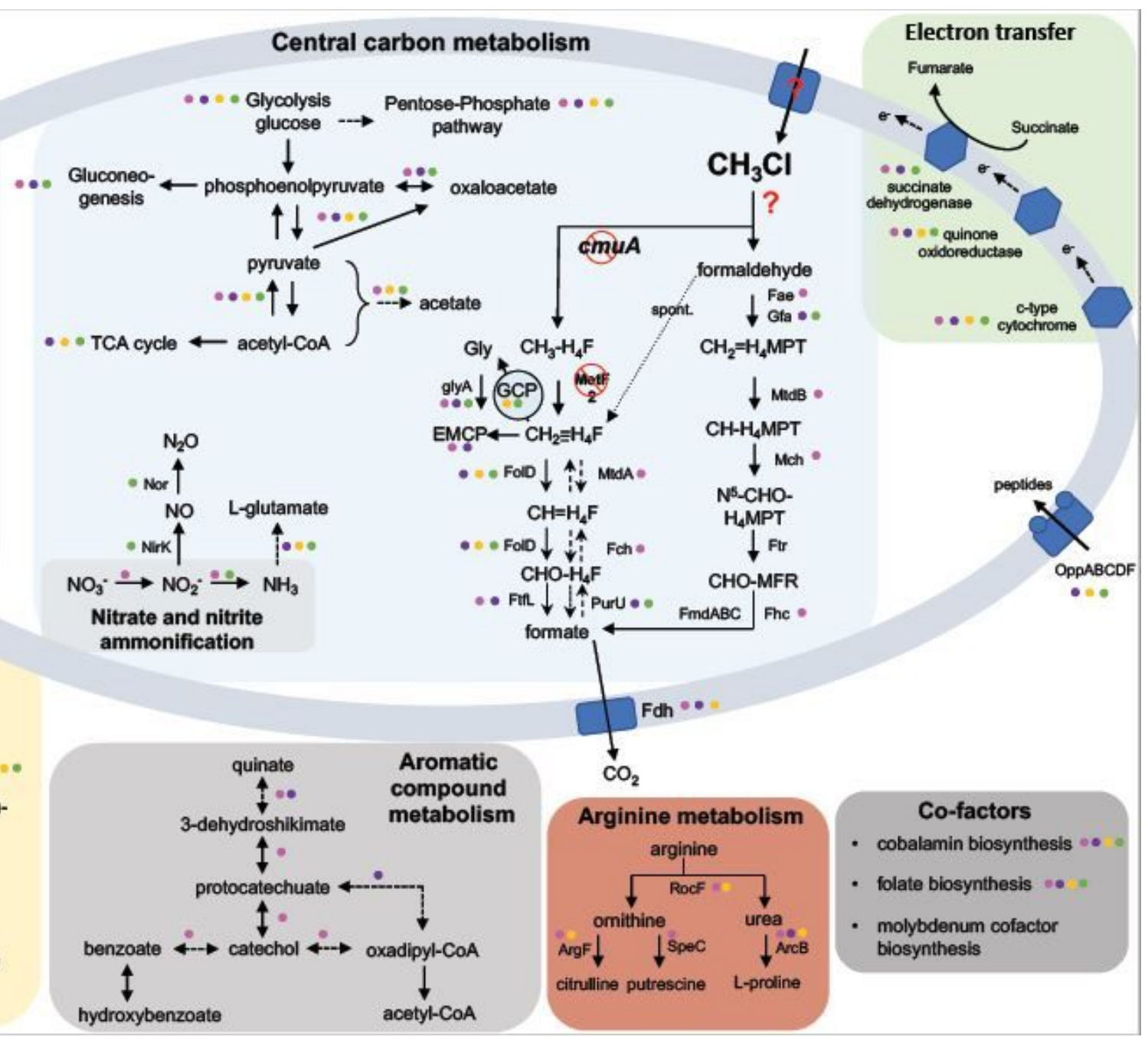

\section{Figure 3}

Due to technical limitations, the caption for figure 3 can be found in the manuscript file.

A

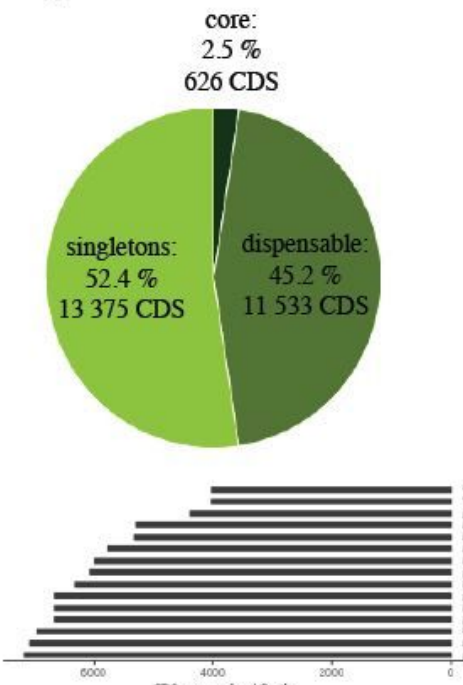

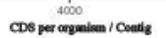

B

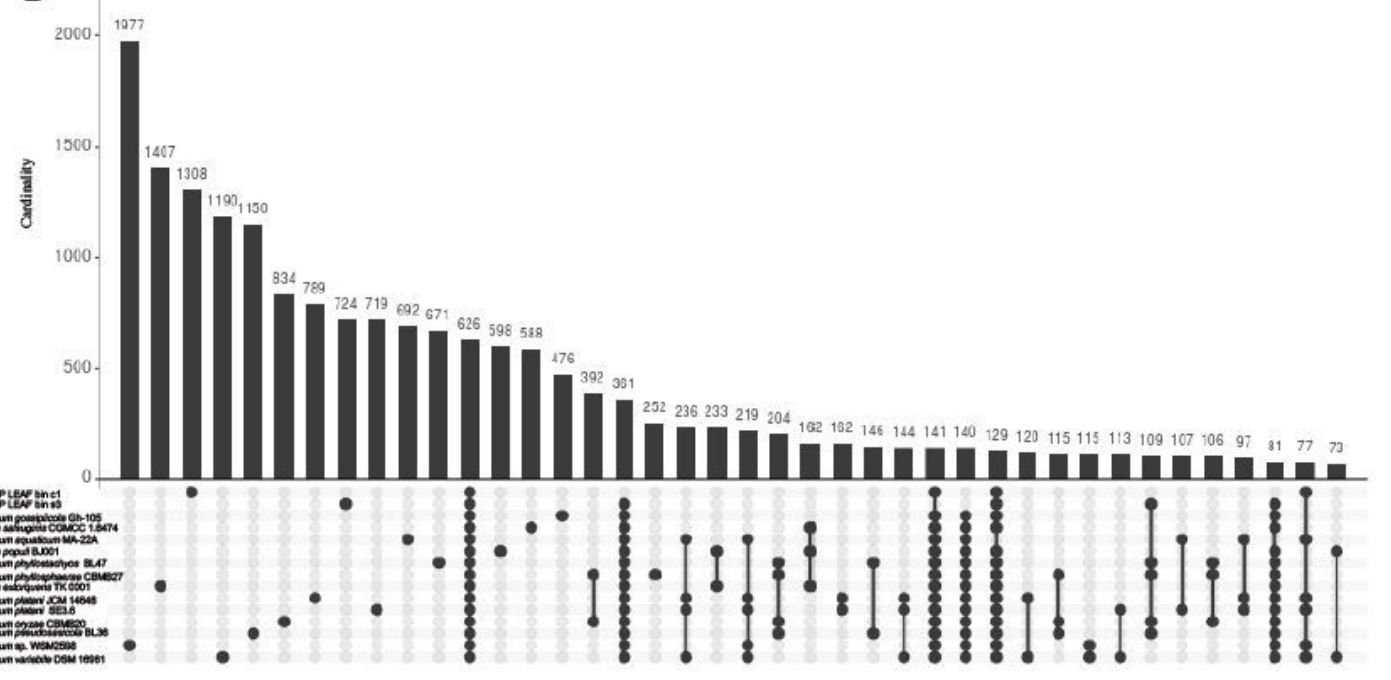


Pan-genome analysis of 13 Methylobacterium genomes of isolated strains and two [13C]-CH3Cl-enriched fern leaf MAGs. (A) Fractional pan genome representation. (B) UpSet plot of the pan-genome of the 15 Methylobacterium genomes. The metagenomic bin 'Fern CH3Cl SIP LEAF bin s3' was chosen as reference genome. The analysis was carried out using the "Efficient Database framework for comparative Genome Analyses using BLAST score Ratios" (EDGAR) platform. 